OPEN ACCESS

Edited by:

Tae Ho Lee,

Fujian Medical University, China

Reviewed by:

Giannino Del Sal,

Consorzio Interuniversitario per le

Biotecnologie, Italy

Eric W. C. Tse,

The University of Hong Kong,

Hong Kong

*Correspondence:

Yandan Yao

yaoyand@mail.sysu.edu.cn

Man-Li Luo

Iuomli@mail.sysu.edu.cn

${ }^{\dagger}$ These authors have contributed equally to this work

Specialty section:

This article was submitted to

Cell Growth and Division,

a section of the journal

Frontiers in Cell and Developmental

Biology

Received: 20 September 2019

Accepted: 22 November 2019

Published: 06 December 2019

Citation:

Huang S, Chen Y, Liang Z-M,

Li N-N, Liu Y, Zhu Y, Liao D, Zhou XZ, Lu KP, Yao Y and Luo M-L (2019)

Targeting Pin 1 by All-Trans Retinoic Acid (ATRA) Overcomes Tamoxifen

Resistance in Breast Cancer via

Multifactorial Mechanisms.

Front. Cell Dev. Biol. 7:322.

doi: 10.3389/fcell.2019.00322

\section{Targeting Pin1 by All-Trans Retinoic Acid (ATRA) Overcomes Tamoxifen Resistance in Breast Cancer via Multifactorial Mechanisms}

\author{
Songyin Huang ${ }^{1 \dagger}$, Yang Chen ${ }^{1 \dagger}$, Zhi-Mei Liang ${ }^{2,3}, \mathrm{Na}-\mathrm{Na} \mathrm{Li}^{2,3}$, Yujie Liu' ${ }^{2,4}$, Yinghua Zhu ${ }^{2,3}$, \\ Dingzhun Liao', Xiao Zhen Zhou', Kun Ping Lu' ${ }^{6}$, Yandan Yao ${ }^{2,4 *}$ and Man-Li Luo ${ }^{2,3 *}$ \\ ${ }^{1}$ Department of Clinical Laboratory, Sun Yat-sen Memorial Hospital, Sun Yat-sen University, Guangzhou, China, \\ ${ }^{2}$ Guangdong Provincial Key Laboratory of Malignant Tumor Epigenetics and Gene Regulation, Sun Yat-sen Memorial \\ Hospital, Sun Yat-sen University, Guangzhou, China, ${ }^{3}$ Medical Research Center, Sun Yat-sen Memorial Hospital, Sun \\ Yat-sen University, Guangzhou, China, ${ }^{4}$ Breast Tumor Center, Sun Yat-sen Memorial Hospital, Sun Yat-sen University, \\ Guangzhou, China, ${ }^{5}$ Department of Pathology, Sun Yat-sen Memorial Hospital, Sun Yat-sen University, Guangzhou, China, \\ ${ }^{6}$ Division of Translational Therapeutics, Department of Medicine, Beth Israel Deaconess Medical Center, Harvard Medical \\ School, Boston, MA, United States
}

Breast cancer is the most prevalent tumor in women worldwide and about $70 \%$ patients are estrogen receptor positive. In these cancer patients, resistance to the anticancer estrogen receptor antagonist tamoxifen emerges to be a major clinical obstacle. Peptidyl-prolyl isomerase Pin1 is prominently overexpressed in breast cancer and involves in tamoxifen-resistance. Here, we explore the mechanism and effect of targeting Pin1 using its chemical inhibitor all-trans retinoic acid (ATRA) in the treatment of tamoxifen-resistant breast cancer. We found that Pin1 was up-regulated in tamoxifenresistant human breast cancer cell lines and tumor tissues from relapsed patients. Pin1 overexpression increased the phosphorylation of $\mathrm{ER} \alpha$ on S118 and stabilized ER $\alpha$ protein. ATRA treatment, resembling the effect of Pin1 knockdown, promoted ER $\alpha$ degradation in tamoxifen-resistant cells. Moreover, ATRA or Pin1 knockdown decreased the activation of ERK1/2 and AKT pathways. ATRA also reduced the nuclear expression and transcriptional activity of ER $\alpha$. Importantly, ATRA inhibited cell viability and proliferation of tamoxifen-resistant human breast cancer cells in vitro. Slow-releasing ATRA tablets reduced the growth of tamoxifen-resistant human breast cancer xenografts in vivo. In conclusion, ATRA-induced Pin1 ablation inhibits tamoxifenresistant breast cancer growth by suppressing multifactorial mechanisms of tamoxifen resistance simultaneously, which demonstrates an attractive strategy for treating aggressive and endocrine-resistant tumors.

\section{Keywords: ATRA, Pin1, breast cancer, tamoxifen, ER $\alpha$}

\section{INTRODUCTION}

Breast cancer is a leading cause of cancer-related death in female (Chen et al., 2016). In all breast cancer patients, approximately $70 \%$ patients are estrogen receptor positive (Deroo and Korach, 2006; Yager and Davidson, 2006; Nilsson et al., 2011). Although selective estrogen receptor modulator such as tamoxifen are effective for ER positive patient, approximately $30 \%$ of patients 
are not sensitive to tamoxifen treatment at the beginning, and over $50 \%$ of initial effective patients finally suffer from tamoxifen-resistance (TAMR) (Osborne and Schiff, 2011). The mechanism of TAMR is still not completely known. The possible molecular mechanisms include, but not limited to, the alteration of estrogen receptor transcriptional co-regulatory proteins (Shao et al., 2004; Girault et al., 2006), cross-talk between receptor tyrosine kinase signaling and estrogen receptor (Stenoien et al., 2001), non-canonical transcriptional activation of estrogen receptor (Anbalagan and Rowan, 2015), the expression of specific microRNAs (Miller et al., 2008), etc. Given that many studies have demonstrated that estrogen receptors play a central role in TAMR (Wijayaratne and McDonnell, 2001; Marsh et al., 2017; Zhang et al., 2017), blocking estrogen receptor related pathways is an attractive strategy to treat TAMR breast cancer.

Pin1 is a peptidyl-prolyl cis/trans isomerase (PPIase), which specifically recognizes pSer/Thr-Pro motifs of proteins and catalyzes their trans-cis conformational change ( $\mathrm{Lu}$ and Zhou, 2007). Pin 1 plays a vital role in cancer development by regulating more than 40 oncoproteins and over 20 tumor suppressors, therefore promoting cancer growth and cancer stem cell tumorigenesis (Zhou and Lu, 2016). Pin1 has been found to be up-regulated in tamoxifen-resistant breast cancer (Stanya et al., 2008; Namgoong et al., 2010; Khanal et al., 2012). Overexpression of Pin 1 reduces the protein stability of estrogen receptor transcriptional co-regulatory protein SMRT (Stanya et al., 2008), as well as regulates the transcription function of $\mathrm{ER} \alpha$ (Rajbhandari et al., 2012, 2015). Knockdown of Pin 1 by siRNA inhibits the viability of TAMR breast cancer cells (Namgoong et al., 2010), indicating that Pin1 might be a promising therapeutic target for tamoxifen-resistant breast cancer. However, due to the lack of appropriate Pin 1 inhibitors, it is challenging to evaluate the effect of targeting Pin 1 on overcoming TAMR. Recently, Wei et al. has discovered all-trans retinoic acid (ATRA) as a specific Pin1 chemical inhibitor (Wei et al., 2015). ATRA has been used to induce differentiation and treat acute promyelocytic leukemia (APL). In APL, ATRA facilitates PML-RAR- $\alpha$ degradation, thereby suppresses APL stem cells (Huang et al., 1988; de The and Chen, 2010; Sanz and Lo-Coco, 2011). Wei et al. (2015) has found that besides RAR, Pin 1 is a key target of ATRA in APL and breast cancer. ATRA directly and selectively binds to and degrades active Pin1, thereby inhibiting multiple Pin1-regulated cancer driving pathways.

In the current study, we explored the effects of ATRA in inhibiting Pin 1 and treating tamoxifen-resistant breast cancer in vitro and in vivo. Our experiments showed that Pin 1 was up-regulated in tamoxifen-resistant cells and increased ER $\alpha$ protein stability. ATRA treatment accelerated ER $\alpha$ protein turnover, reduced ER $\alpha$ transcriptional activity, and decreased the phosphorylation of AKT and ERK1/2 simultaneously, which further inhibited ER $\alpha$ activation. Thus, ATRA induced the degradation of Pin 1 and suppressed cell viability and proliferation of tamoxifen-resistant breast cancer cells. More importantly, slow-releasing ATRA tablets showed remarkable anti-tumor effects in the tamoxifen-resistant xenograft model. Therefore, targeting Pin 1 by ATRA promised a new potential approach to treat tamoxifen-resistant breast cancer.

\section{MATERIALS AND METHODS}

\section{Cell Culture}

The human breast cancer cell lines MCF7 and T47D were purchased from American Type Culture Collection (Manassas, VA, United States) and cultured in DMEM (Thermo Fisher Scientific, Waltham, MA, United States) supplemented with 10\% fetal bovine serum (FBS, GBICO). Tamoxifen resistant cell lines (MCF-7R and T47DR) were kindly provided by Dr. Qiang Liu as gift, and were cultured in no-phenol red 1640 medium (Life Technologies, United States) supplemented with 10\% charcoalstripped FBS (cFBS) (HyClone, United States) and $1 \mu \mathrm{M} 4$ hydroxytamoxifen (Sigma-Aldrich, St. Louis, MO, United States). Cells were maintained at $37^{\circ} \mathrm{C}$ in a humidified atmosphere containing $5 \% \mathrm{CO}_{2}$.

\section{Antibodies, Reagents, and Sequences}

Antibodies of ER $\alpha$ was from cell signaling technology (8644) and Abcam (16660). Antibodies of Pin1 was from R\&D (MAB2294) and Abnova (MAB12340). Phospho-ER $\alpha$ S1 18 antibody was from Abcam (ab32396). Phospho-ER $\alpha$ S167 antibody was from cell signaling technology (64508). ATRA was from Sigma (R2625). Tamoxifen was from Sigma (H6278). Pin1 shRNA targeting sequence: CCACCGTCACACAGTATTTAT; Pin1 siRNA-1 targeting sequence: TCAGGCCGAGTGTACTACT; Pin1 siRNA2 targeting sequence: GCTCAGGCCGAGTGTACTA; RAR $\alpha$ siRNA-1 targeting sequence: CCAGCTCACAGAACTGCTT; RAR $\alpha$ siRNA-2 targeting sequence: TTCCGCACGTAGACCTT TAGC; ER $\alpha$ siRNA-1 targeting sequence: CAGGCCAAATTCA GATAAT; $\mathrm{ER} \alpha$ siRNA-2 targeting sequence: GGTCCAC CTTCTAGAATGT.

\section{Colony-Forming Assays}

Six-well plates were seeded 2000 cells per well. Cells were treated with vehicle (DMSO), $10 \mu \mathrm{M}$ ATRA, $10 \mu \mathrm{M}$ tamoxifen (TAM) or ATRA plus TAM, and medium were changed every 3 days. 14 days later cells were fixed with methanol, stained with $0.5 \%$ crystal violet.

\section{Cell Viability Assays}

Cell viability was measured using the Cell Titer Glo reagent (Promega). The cells were plated in 96-well plates at $1 \times 10^{3}$ cells per well and maintained at $37^{\circ} \mathrm{C}$. At the indicated time points, cell viability was measured according to the manufacturer's instructions.

\section{Quantitative RT-PCR}

Total RNA was extracted from cells using Trizol (life, United States). MMLV kit (life, United States) was used to generate CDNA. Real time PCR were performed using Toyobo SYBR GREEN. The primers used were as follows: Pin1 (forward, 5' - AGCTCAGGCCGAGTGTACTA-3'; reverse, 5'-CCTTGGTCCGGGTGATCTTC -3'); growth regulation by estrogen in breast cancer 1 (GREB1) (forward, 5'-GTGGT AGCCGAGTGGACAAT-3'; reverse, 5' -ATTTG TTTCCAGCC CTCCTT-3'); progesterone receptor (PGR) (forward, 5'-GG 
CATGGTCCTTGGAGGT -3'; reverse, 5'-CCACTGGCTGTGG GAGAG-3'); c-Myc (forward, 5'- TACAACACCC GAGC AAGGAC-3'; reverse, 5'-GAGGCTGCTGGTTTTCCACT-3'); $\beta$-actin (forward, $5^{\prime}$-GGAAGGGGGACGGGGACAGC-3'; reverse, 5' - GGAGGAGCAAG GAGCGGGAG-3').

\section{Immunoblot Analysis}

Cells were lysed with RIPA buffer containing $0.1 \%$ protease inhibitors or phosphatase inhibitors (Life, United States). The supernatant of lysate was separated by electrophoresis and blotted onto a PVDF membrane, then blocked with $5 \%$ skim milk at room temperature for $1 \mathrm{~h}$. The blots were incubated with the following antibody at $4^{\circ} \mathrm{C}$ overnight: $\mathrm{ER} \alpha(1: 1000$, CST, \#8644); Pin1 (1:1000, R\&D, \#MAB2294); phospho-ER $\alpha$ S118 (1:1000, CST, \#ab32396); AKT (1:1000, CST); Flagtag (1:5000, Sigma, United States); phospho-AKT (1:1000, CST); phospho-c-Raf (1:1000, CST); phospho-MEK1/2 (1:1000, CST); ERK1/2 (1:1000, CST); phospho-ERK1/2 (1:1000, CST); phospho-ER $\alpha$ S167 (1:1000, CST, \#64508); $\beta$-Actin (1:2000, CST); GAPDH (1:2000, proteintech). After incubation with HRPconjugated secondary antibodies at room temperature for $1 \mathrm{~h}$, all blots were detected by an enhanced chemiluminescence (ECL) and were scanned using ChemiDoc ${ }^{\mathrm{TM}}$ XRS + imaging system (Bio-Rad, Hercules, CA, United States).

\section{Immunofluorescence}

MCF-7R and T47DR cells were fixed in 4\% polyoxymethylene at $4{ }^{\circ} \mathrm{C}$ for $20 \mathrm{~min}$, washed with PBS and permeabilized in $0.1 \%$ Triton X-100 at room temperature for $10 \mathrm{~min}$. Cells were then blocked in $10 \%$ goat serum at room temperature for $30 \mathrm{~min}$, and incubated with ER $\alpha$ antibody (1:100, Abcam, \#16660) in $10 \%$ goat serum at $4^{\circ} \mathrm{C}$ overnight. Cells were washed, incubated with secondary antibodies at room temperature for $1 \mathrm{~h}$, washed, incubated with DAPI at room temperature for $15 \mathrm{~min}$. Slides were then covered with fluorescently quencher $30 \mu \mathrm{l}$, sealed and photographed with an Olympus confocal microscope.

\section{Animal Experiments}

Nude mice were purchased from Laboratory Animal Service Center, Sun Yat-sen University. The experiment protocol was approved by the Animal Care and Use Committee of Sun Yatsen University. $2 \times 10^{6}$ MCF-7R cells were mixed with an equal volume of matrigel (Corning) and injected into the mammary fat pads of 4 week-old female BALB/c nude mice. One week later, when tumor size reached $\sim 100 \mathrm{~mm}^{3}$, the tumor-bearing mice were randomized into treatment groups. 21-days ATRA tablets were implanted under neck skin. Tamoxifen was injected at $4 \mathrm{mg} / \mathrm{kg}$ per day. Tumor volume was measured every 3 days.

\section{Patients and Immunohistochemistry}

Tumor samples were obtained from patients with ER positive breast cancer who underwent tamoxifen therapy in Sun Yat-sen Memorial Hospital. All samples were collected from patients with informed consent, and all related procedures were performed with the approval of the internal review and ethics boards of Sun Yat-sen Memorial Hospital. Immunohistochemistry staining for Pin1 and ER $\alpha$ was performed as described previously (Luo et al., 2015; Zhang et al., 2016). Briefly, sodium citrate was used to repair tissue antigen. Incubation of primary antibodies (Pin1, 1:50, Abnova, \#MAB12340; ER $\alpha, 1: 50$, CST, \#16660) was carried out at $4^{\circ} \mathrm{C}$ overnight. The slides were incubated with HRP-conjugated secondary antibodies at room temperature for $1 \mathrm{~h}$, washed, visualized with DAB solution, followed by staining with hematoxylin. Immunostaining results was analyzed by ImageJ software.

\section{Statistical Analyses}

All data are presented as the means $\pm \mathrm{SD}$. Student's $t$-test was used to analysis the significance between two experimental groups, and ANOVA test was used to analysis among three or more groups. $P<0.05$ was considered significant. All the statistical analyses were performed using SPSS20.

\section{RESULTS}

\section{Pin1 Is Up-Regulated in Tamoxifen-Resistant Breast Cancer and Correlates With ER $\alpha$ Expression in Human Breast Cancer Cell Lines and Cancer Tissues}

We established tamoxifen-resistant human breast cancer cell lines MCF-7 and T47D by long-term exposure to tamoxifen (Herman and Katzenellenbogen, 1996; Knowlden et al., 2003; Chu et al., 2015). We confirmed the resistance of these cells by showing that the viability of resistance cells was significantly higher than parental cells and apoptosis were remarkable lower in the presence of $1 \mu \mathrm{M}$ tamoxifen (Chu et al., 2015). We found that both Pin1 protein and mRNA were up-regulated in tamoxifen-resistant MCF-7 (MCF-7R) and T47D (T47DR) cells, comparing to parental cells (Figures 1A-E and Supplementary Figure S5), which was consistent with previous reports that Pin1 was overexpressed in TAMR human breast cancer tissues (Namgoong et al., 2010; Khanal et al., 2012).

Although ER $\alpha$ was not so indispensable for TAMR cells as for parental cells, depleting ER $\alpha$ still further limited the growth of TAMR cells (Xiong et al., 2017). Indeed, through a variety of mechanisms, TMAR breast cancer cells made full use of remaining ER $\alpha$ to escape from the impact of tamoxifen (Osborne and Schiff, 2005; Johnston, 2010; Marsh et al., 2017). Here we examined the ER $\alpha$ level in TAMR cells, and found that ER $\alpha$ protein was down-regulated in TAMR cells (Figures 1F-H and Supplementary Figure S5), as shown previously (Stone et al., 2013; Lu et al., 2016). Given that ER $\alpha$ was a known Pin1 substrate which was positively regulated by Pin1 (Rajbhandari et al., 2012, 2015). We asked why Pin 1 level was high while ER $\alpha$ level was low in TAMR cells. We found that Pin 1 knockdown further decreased ER $\alpha$ level in TAMR cell lines (Figures 1I-L and Supplementary Figure S5). These results suggest that Pin1 is up-regulated and helps maintain ER $\alpha$ levels in TAMR cells even although ER $\alpha$ levels in these cells are low. 


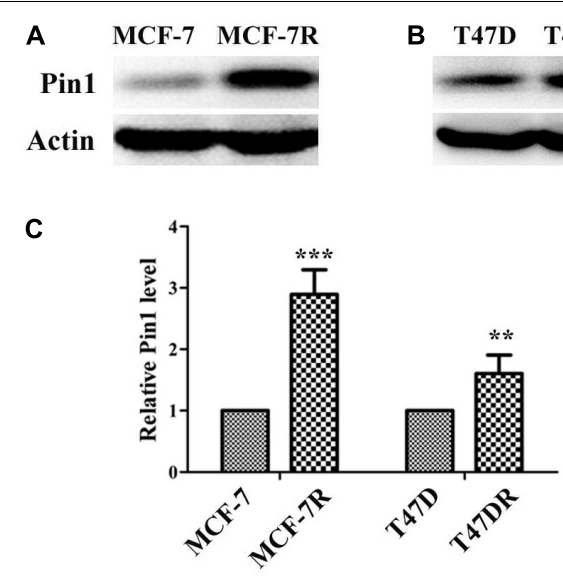

F

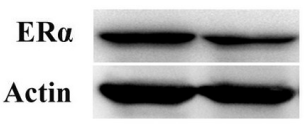

H

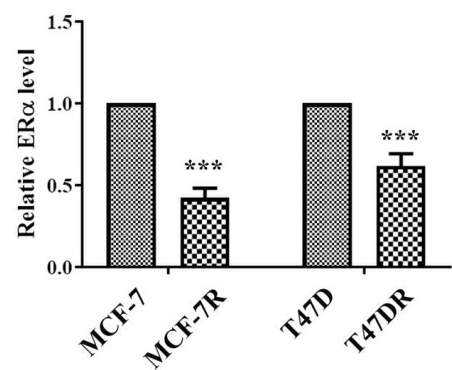

G T47D T47DR

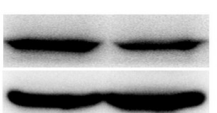

D

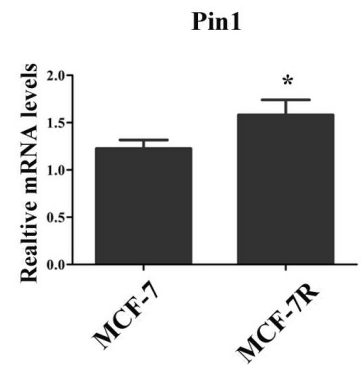

I

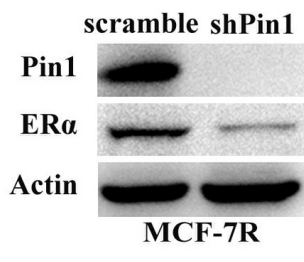

K

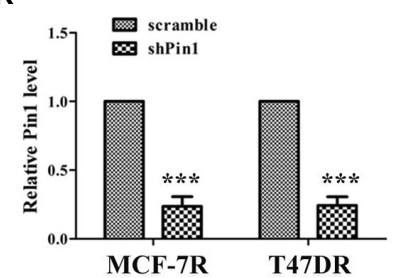

E Pin1

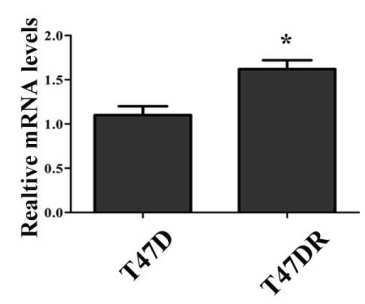

J scramble shPin1

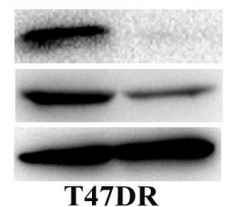

T47DR

L

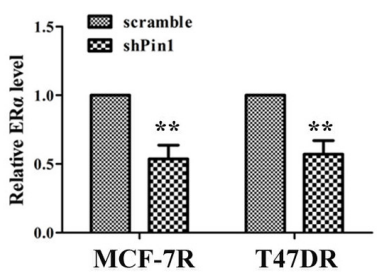

FIGURE 1 | Pin1 is overexpressed in tamoxifen resistant breast cancer cells. (A,B) Pin1 is up-regulated in tamoxifen resistant breast cancer cells. Pin1 protein was detected by western blot in parental (MCF-7 and T47D) and tamoxifen resistant (MCF-7R and T47DR) cells. (C) Quantification of Pin1 levels in parental and tamoxifen resistant cells. Western blot bands in panels $(\mathbf{A}, \mathbf{B})$ were quantified by densitometric scan and represented as a relative ratio to control samples. Data are represented as means \pm SD for three independent experiments. (D,E) Pin1 mRNA is up-regulated in tamoxifen resistant breast cancer cells, as detected by qRT-PCR. (F-H) The ER $\alpha$ protein level in parental and resistant breast cancer cells. Western blot bands were quantified in panel (H). (I-L) Pin1 knockdown decreases the level of ER $\alpha$ in MCF-7R and T47DR cells. Western blot bands were quantified in panels (K,I). ${ }^{*} P<0.05,{ }^{* *} P<0.01,{ }^{* * *} P<0.001$.

Next, we detected Pin 1 and $\mathrm{ER} \alpha$ protein levels in tumor tissues of recurrent ER positive breast cancer patients, who have received tamoxifen treatment. Pin1 protein level was significantly higher in recurrent tumors comparing with primary tumors $(P=0.004)$ (Figures 2A,B). More importantly, the expression level of Pin1 was associated with ER $\alpha$ in these tissues (Figures 2C,D). Together, Pin1 was up-regulated in both TAMR human breast cancer cell lines and relapsed tumor tissues, which positively correlated with $\mathrm{ER} \alpha$ expression.

\section{ATRA-Induced Pin1 Ablation Promotes ER $\alpha$ Protein Degradation}

To explore the effect of Pin1 on regulating $\mathrm{ER} \alpha$, and more importantly to test whether ATRA was effective in inhibiting Pin1's function on $\mathrm{ER} \alpha$, we first examined whether overexpressing Pin1 affected ER $\alpha$ protein level. As expected, estradiol (E2) could induce down-regulation of $\mathrm{ER} \alpha$ protein
(Figures 3A,B and Supplementary Figure S6), which was due to ligand-dependent degradation (Wijayaratne and McDonnell, 2001; Nonclercq et al., 2004). We found that not only enforced Pin1 expression (Flag-Pin1) rescued the ER $\alpha$ expression, but the Pin1 inhibitor ATRA reversed this effect in both MCF7 and MCF-7R cells (Figures 3A,B and Supplementary Figures S1A,B), suggesting that ATRA specifically inhibiting Pin1 from protecting the degradation of $\operatorname{ER} \alpha$.

Next, to confirm the effect of ATRA on ER $\alpha$ protein degradation, MCF-7 and MCF-7R cells stably knocking down Pin1 with shRNA were treated with or without proteasome inhibitor MG132. Contrary to overexpression experiments, Pin1 knockdown promoted E2-induced ER $\alpha$ degradation (Figures 3C,D and Supplementary Figures S1C,D). Notably, ATRA had the same effects as shPin1 both in MCF-7 and MCF7R cells (Figures 3C,D and Supplementary Figures S1C,D). One of the vital regulatory element governing $\mathrm{ER} \alpha$ protein turnover is Ser118 phosphorylation of the N-terminus, which is 


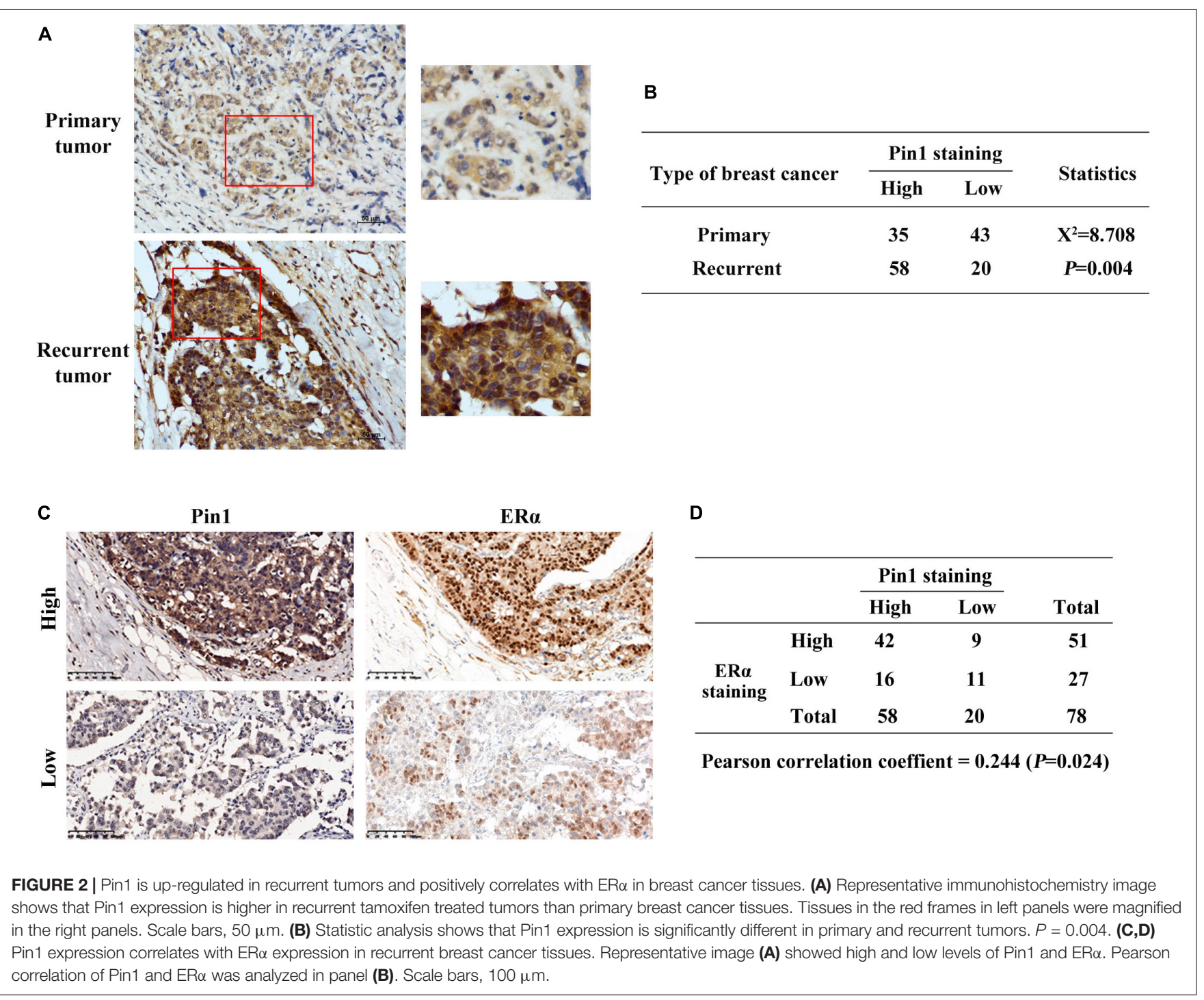

phosphorylated by ERK1/2 as well as other kinases, and regulated by Pin1 (Rajbhandari et al., 2012, 2014, 2015). Therefore we speculated that ATRA promoted ER $\alpha$ protein turnover through ER $\alpha$-pS118. Indeed, overexpressing Pin1 increased the phosphorylation of S118 as well as total ER $\alpha$ level, suggesting that Pin 1 prevented the turnover of $\mathrm{pER} \alpha$, whereas ATRA reversed Pin1's effect (Figure 3E and Supplementary Figures S1E,F).

To directly examine whether ATRA could promote the degradation of Pin 1 and $\mathrm{ER} \alpha$ in tamoxifen-resistant cells, we treated MCF-7R and T47DR cells with ATRA, followed by cycloheximide $(\mathrm{CHX})$ and detected the protein levels at different time points. Our data showed that ATRA promoted the degradation of both Pin 1 and ER $\alpha$ in TAMR breast cancer cells in a dose dependent manner (Figures 3F,G and Supplementary Figures S1G-J). In addition, we treated MCF-7R and T47DR cells with increasing doses of ATRA for different length of time, and found that both Pin 1 and $\mathrm{ER} \alpha$ protein levels indeed reduced (Supplementary Figures S2A,B, S9). Together, these data demonstrate that overexpressing Pin 1 in breast cancer cells protects the ER $\alpha$ protein from degradation. ATRA blocks the upregulated Pin1 in tamoxifen-resistant cells, thereby promoting the degradation of remaining $\mathrm{ER} \alpha$ in tamoxifen-resistant cells, which suggests that ATRA may be able to overcome TAMR by eradicate $\mathrm{ER} \alpha$.

\section{ATRA Blocks ERK1/2 and AKT Pathways in TAMR Breast Cancer Cells}

Several kinase pathways have been reported to involve in the growth of TAMR breast cancer cells, including AKT and ERK1/2 (Svensson et al., 2005; Garcia-Becerra et al., 2012). AKT phosphorylates ER $\alpha$ on S167 (Sun et al., 2001), and ERK1/2 phosphorylates ER $\alpha$ on S104/S106, S167, and S118 (Ali et al., 1993; Arnold et al., 1995; Endoh et al., 1999; Sun et al., 2001; Sheeler et al., 2003). Notably, phosphorylation of S118 and S167 induces estrogen-independent activation of ER $\alpha$ (GarciaBecerra et al., 2012). Moreover, AKT and ERK1/2 activity are also regulated by Pin1 (Liao et al., 2009; Luo et al., 2015). Thus, 
A

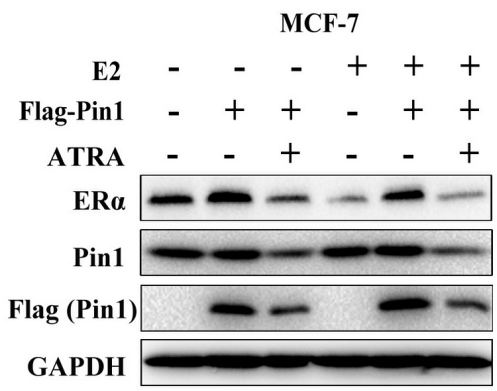

C

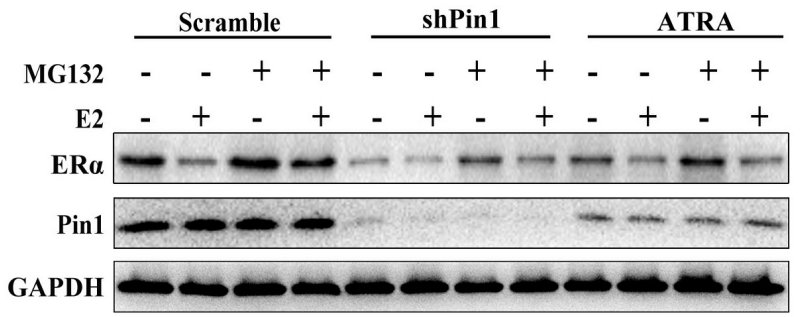

E

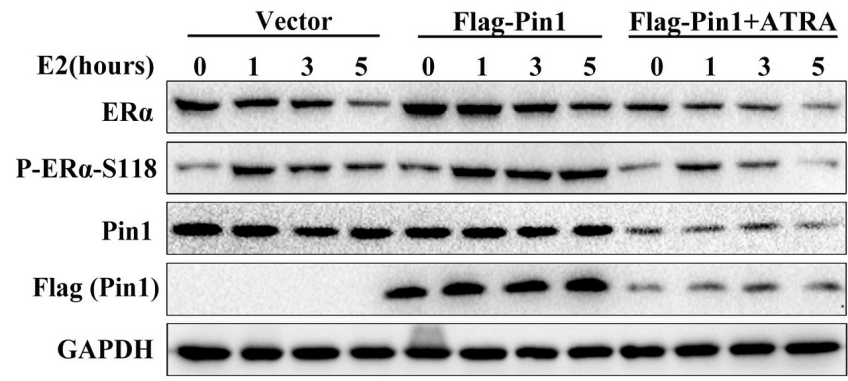

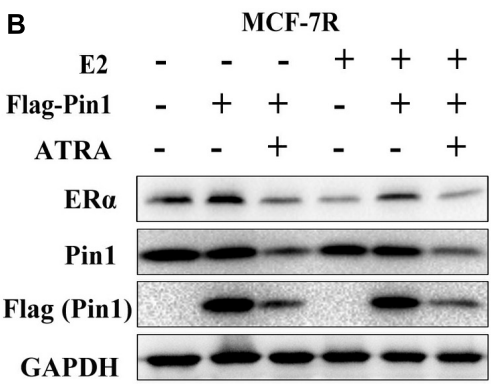

D

MCF-7R

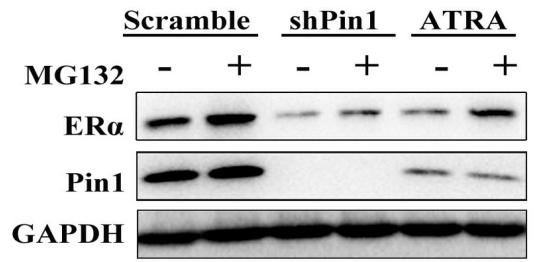

F

MCF-7R

G
T47DR

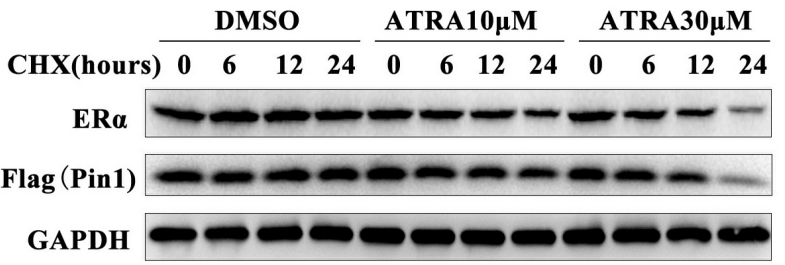

FIGURE 3 | ATRA promotes proteasome-mediated degradation of ER $\alpha$ by blocking Pin1. (A,B) Ectopic expression of Pin1 up-regulates ER $\alpha$, but ATRA abrogates the effect. MCF-7 (A) and MCF-7R (B) cells transfected with Flag-Pin1 or empty vector were pretreated with $10 \mu \mathrm{M}$ ATRA for $72 \mathrm{~h}$, followed by $10 \mathrm{nM}$ E2 or EtOH treatment for 5 h. (C,D) Pin1 knockdown or ATRA treatment promotes ER $\alpha$ degradation. MCF-7 (C) or MCF-7R (D) were treated with $10 \mu \mathrm{M}$ MG132 for $4 \mathrm{~h}$ before harvesting. (E) Overexpression of Pin1 stabilizes pS118-ER $\alpha$, but ATRA abrogates the effect. MCF-7 cells transfected with Flag-Pin1 or empty vector were pretreated with $10 \mu \mathrm{M}$ ATRA for $72 \mathrm{~h}$, followed by 10nM E2 treatment for $0,1,3$, and $5 \mathrm{~h}$. (F,G) ATRA promotes Pin1 and ER $\alpha$ degradation in MCF-7R and T47DR cells. Cells were pretreated with ATRA and treated with $\mathrm{CHX}$ for indicated time course.

we explored the effects of ATRA in inhibiting these pathways in MCF-7R and T47DR cells. ATRA treatment didn't alter the total expression of AKT or ERK1/2, but reduced the level of phosphorylated AKT, MEK1/2, ERK1/2 and Raf (Figures 4A,B). In consistence with decreased activity of these pathways, phosphorylation of ER $\alpha$ on S167 and S118 were also inhibited, resembling the effect of Pin1 knockdown (Figures 4A,B and Supplementary Figure S7).

To assess the effect of ATRA on ER signaling in normal cells, we treated immortalized mammary epithelial cells MCF10A and HMLE with different doses of ATRA. These two cell lines expressed very low level of Pin1, comparing to breast cancer cell 
A

MCF-7R

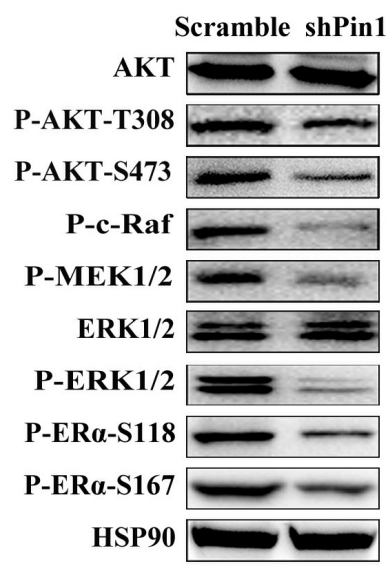

B

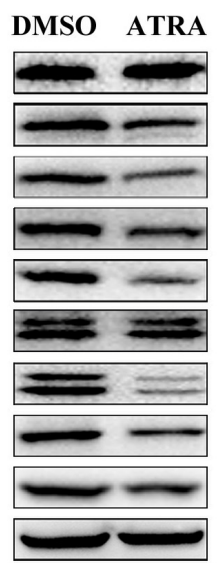

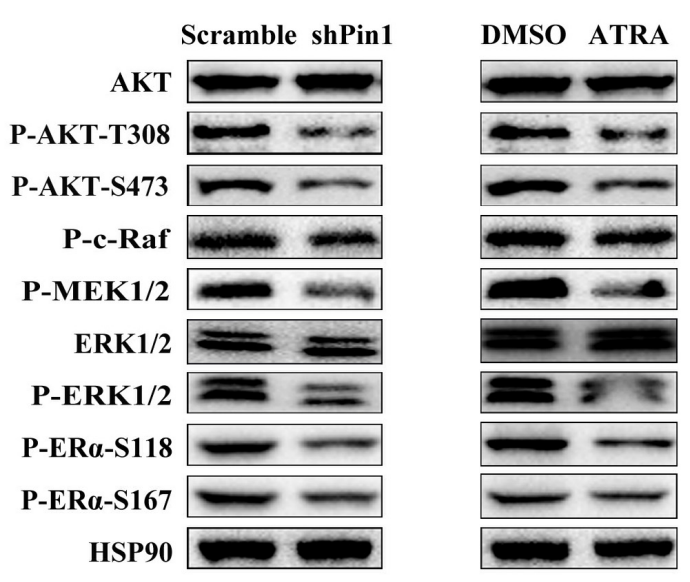

C

HMLE

MCF-10A

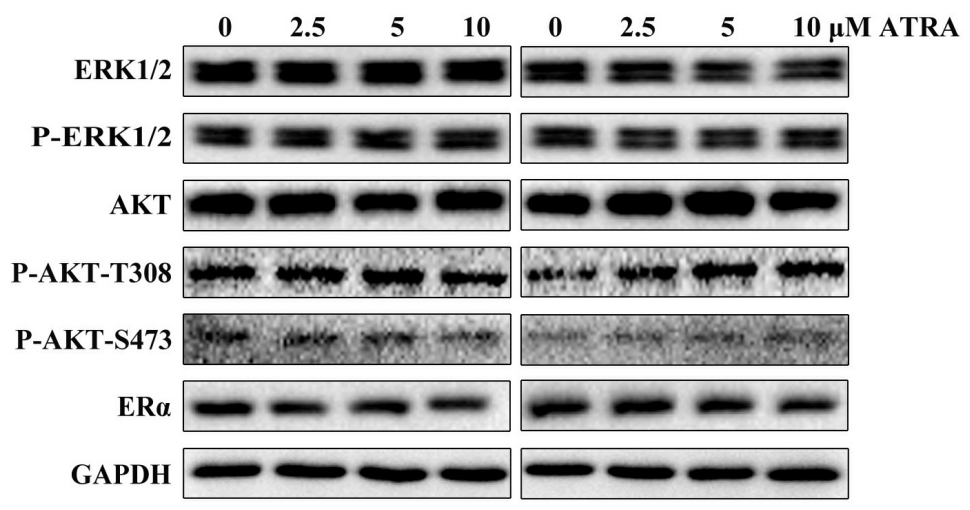

FIGURE 4 | ATRA and Pin1 knockdown inhibits the activation of AKT and ERK1/2 signal pathways. (A) Pin1 knockdown or ATRA treatment inhibits the activation of AKT and ERK $1 / 2$ signal pathways simultaneously in MCF-7R cells. Cells were infected with lentivirus expressing scramble or Pin 1 shRNA, or treated with $10 \mu \mathrm{M}$ ATRA for $72 \mathrm{~h}$. (B) Pin1 knockdown or ATRA treatment decreases the activation of AKT and ERK1/2 signal pathways simultaneously in T47DR cells. (C) ATRA treatment doesn't affect ER $\alpha, A K T$, and ERK1/2 in HMLE and MCF-10A cells.

lines (Wei et al., 2015). We found that ATRA almost had no effect on the protein level of ER $\alpha$, or P-ERK1/2 and P-AKT (Figure 4C). Hence, ATRA had the unique potential to simultaneously block multiple signal pathways in TAMR breast cancer cells.

In addition, $\operatorname{RAR} \alpha$, another ATRA target, has been indicated to play a role in tamoxifen resistance of breast cancer (Johansson et al., 2013). Using siRNAs, we knocked down either Pin 1 or RAR $\alpha$ in MCF-7R cells with or without ATRA treatment (Supplementary Figures S3A,B). The total and phosphorylated levels of $\mathrm{ER} \alpha$ only decreased in Pin1-silencing, but not RAR $\alpha$-silencing cells (Supplementary Figures S3C, S10). As ATRA can still target other proteins to regulate $\mathrm{ER} \alpha$, our data indicate that ATRA may mainly act on Pin 1 to regulate ER $\alpha$.

\section{ATRA Inhibits ER $\alpha$ Transcriptional Activity}

To determine whether ATRA affected the transcriptional function of $\mathrm{ER} \alpha$ in tamoxifen-resistant cells, we first examined
$\mathrm{ER} \alpha$ subcellular expression by immunofluorescence. Parental or resistant MCF-7 and T47D cells were treated with $10 \mu \mathrm{M}$ ATRA for $72 \mathrm{~h}$. The nuclear staining of ER $\alpha$ was dramatically reduced by ATRA treatment in all cell lines (Figures 5A-D), indicating a decreased transcriptional activity of ER $\alpha$. Next, we detected the transcription of three known ER $\alpha$ regulatory genes, including PGR, GREB1, and c-Myc (Lee and Gorski, 1996; Bosch et al., 2015; Wu et al., 2018). The mRNA levels of these three genes were decreased after ATRA treatment (Figures 5E-H). These data suggest that ATRA suppresses ER $\alpha$ transcriptional function in vitro.

\section{ATRA Inhibits the Viability and Proliferation of Parental and Tamoxifen-Resistant Breast Cancer Cells}

Although our data demonstrated that ATRA targeted Pin1 to promote $\mathrm{ER} \alpha$ protein degradation, decrease $\mathrm{ER} \alpha$ transcriptional 
A

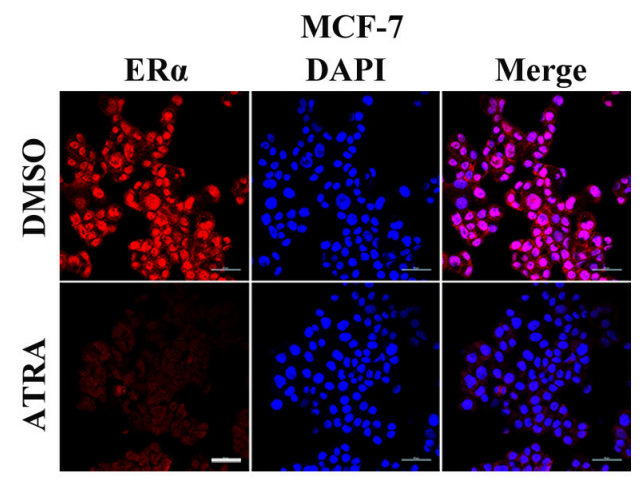

C
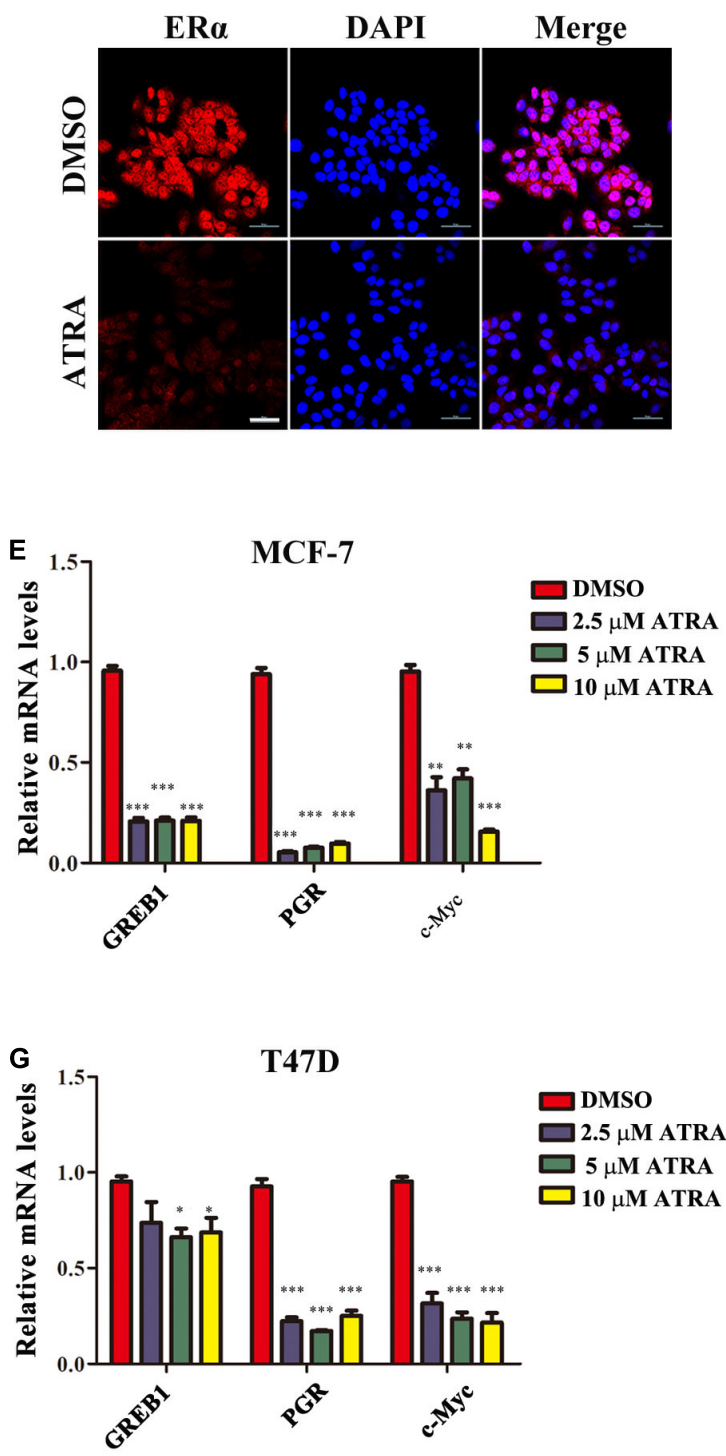

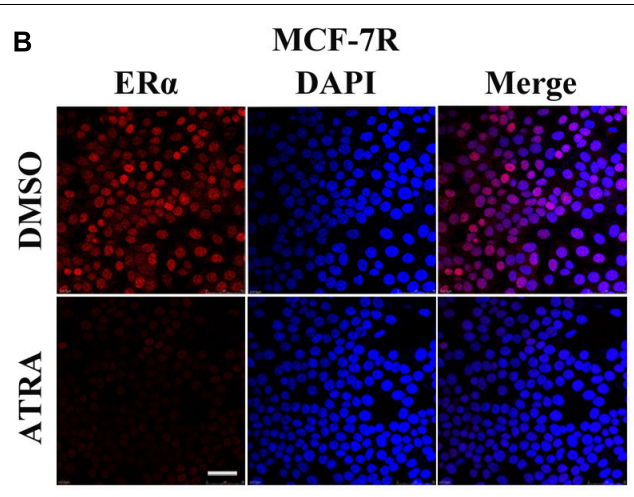

D

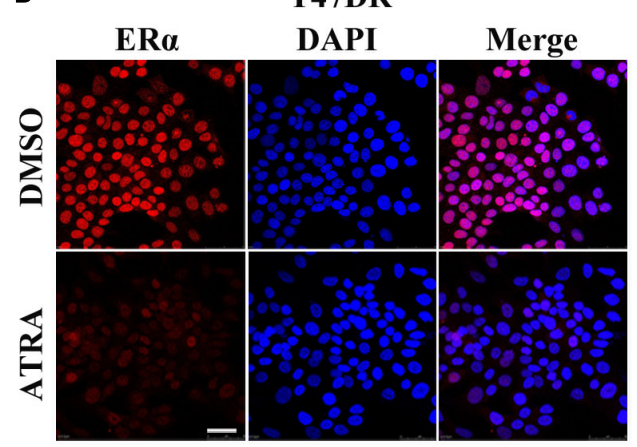

F

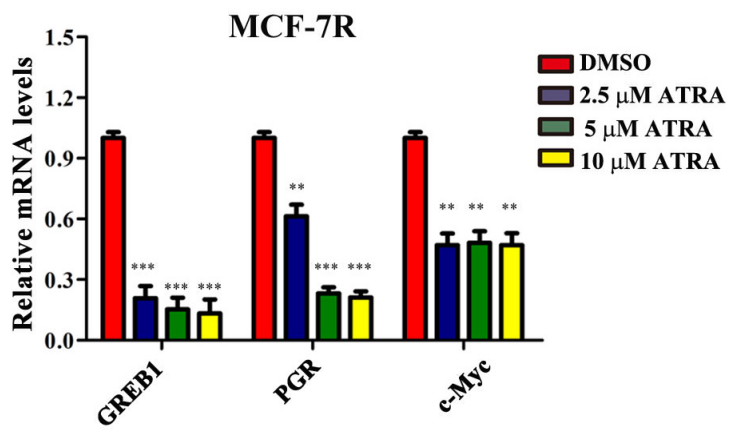

H

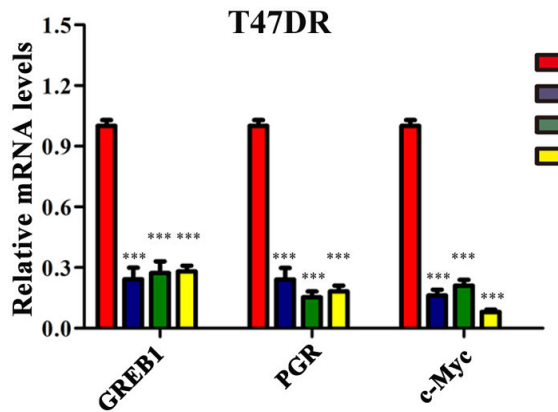

FIGURE 5 | ATRA suppresses nuclear expression and transactivation of ER $\alpha$. (A,B) ATRA decreases the level of nuclear ER $\alpha$ in MCF-7 and MCF-7R. Cells were treated with $10 \mu \mathrm{M}$ ATRA for $72 \mathrm{~h}$ before immunofluorescence staining. Scale bars, $50 \mu \mathrm{m}$. (C,D) ATRA decreases the level of nuclear ER $\alpha$ in T47D and T47DR. Cells were treated with10 $\mu \mathrm{M}$ ATRA for $72 \mathrm{~h}$ before immunofluorescence staining. Scale bars, $50 \mu \mathrm{m}$. (E-H) ATRA suppresses the transcription of ER $\alpha$ target genes GREB1, PGR, and c-Myc. Cells were treated with ATRA (2.5, 5.0, and10 $\mu \mathrm{M})$ for $48 \mathrm{~h}$. Expression of ER $\alpha$ downstream genes were detected by qRT-PCR, and normalized to $\beta$-ACTIN expression in DMSO treated cells. Error bars denote the SD of three biological replicates, ${ }^{*} P<0.05,{ }^{* *} P<0.01, * * * P<0.001$. 
activity, and inhibit AKT and ERK1/2 pathway, the therapeutic potential of ATRA in treating tamoxifen-resistant breast cancer was still not clear. We thus evaluated the effects of ATRA on cell viability and foci formation of parental and TAMR cells. As expected, tamoxifen treatment reduced the growth of parental cells, but not the TAMR cells, whereas ATRA suppressed the proliferation of both parental and TAMR cells (Figures 6A-D). Moreover, ATRA potentiated tamoxifen therapeutic effect in both parental and TAMR cells (Figures 6A-D). In the colony formation experiments, ATRA showed similar effects as in the proliferation assay (Figures 6E-G).

We have shown that ATRA-induced Pin1 degradation reduces the protein expression of $\mathrm{ER} \alpha$ in tamoxifen-resistant breast cancer cells. To confirm that $\mathrm{ER} \alpha$ contributes to tamoxifen resistance in our TAMR cell model, we used siRNAs to knock down $\mathrm{ER} \alpha$ in MCF-7R and T47DR. ER $\alpha$ siRNAs dramatically
A

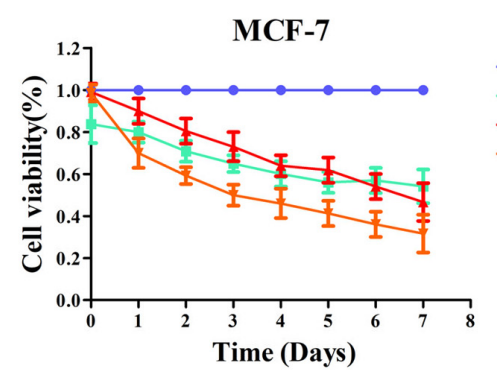

C

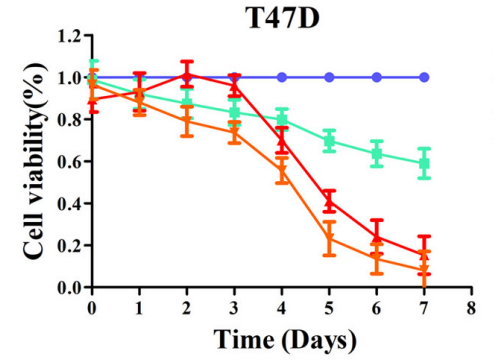

$\rightarrow$ Ctrl

- TAM

$\rightarrow$ ATRA

$*$ TAM+ATRA
B

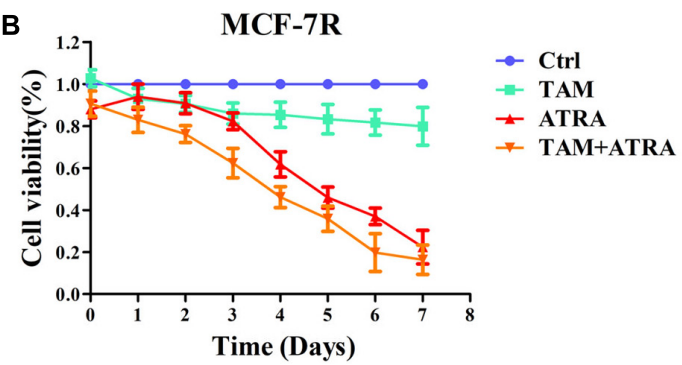

D

- Ctrl

$\rightarrow$ ATRA

$\rightarrow$ TAM+ATRA

T47DR
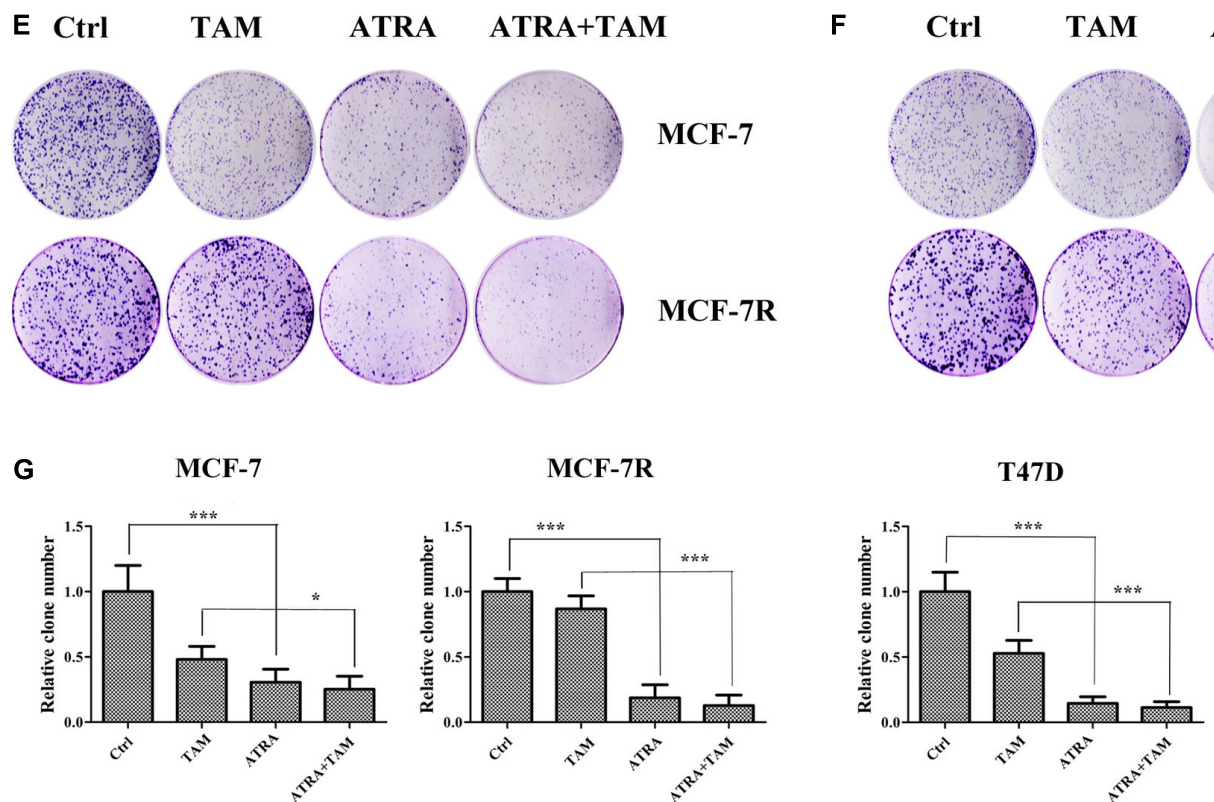

ATRA ATRA+TAM

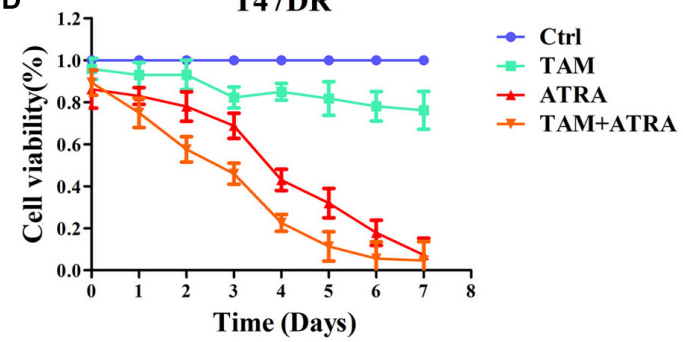

T47D

G

MCF-7R
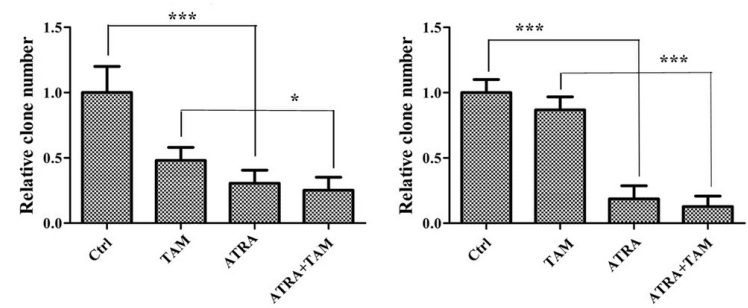

FIGURE 6 | ATRA inhibits the cell growth of tamoxifen resistant breast cancer cells. (A-D) The inhibitory effect of ATRA and tamoxifen on cell viability of parental and tamoxifen resistant breast cancer cells. Viability of drug treated cells was normalized to control untreated cells (Ctrl). (E,F) The inhibitory effect of ATRA and tamoxifen on foci formation of parental and tamoxifen resistant breast cancer cells. (G) Quantification of foci formation by ImageJ software. ${ }^{*} P<0.05$ and ${ }^{* * *} P<0.001$, as determined by Student's $t$-test. Bar graphs are means \pm SD by three independent experiments. 
A

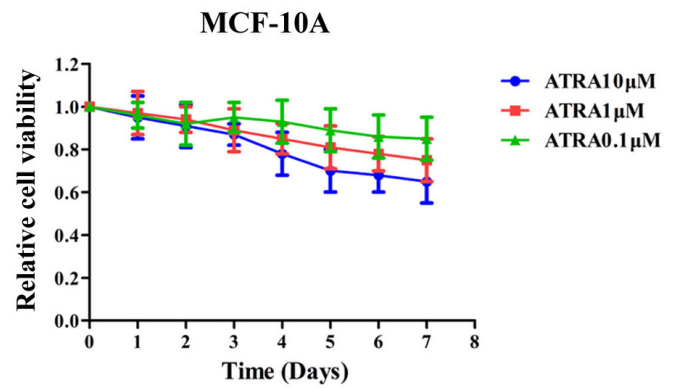

B

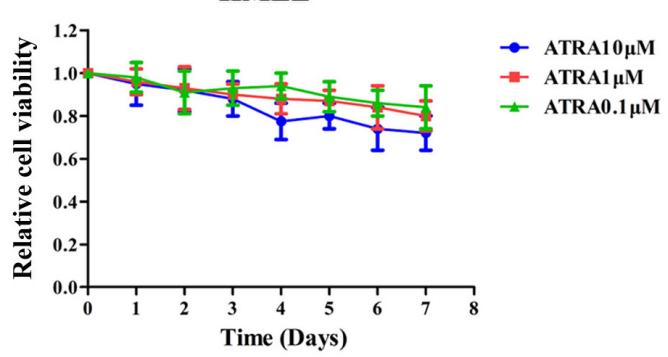

C

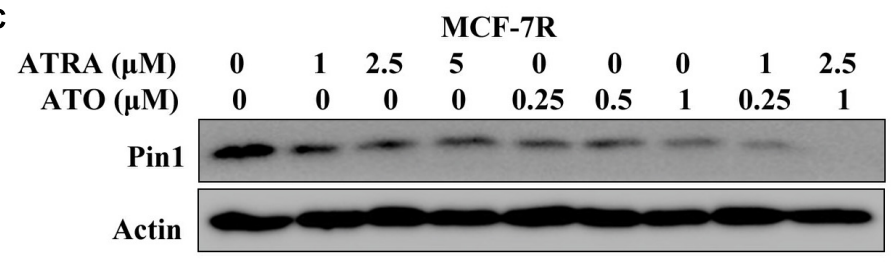

D MCF-7R Scramble
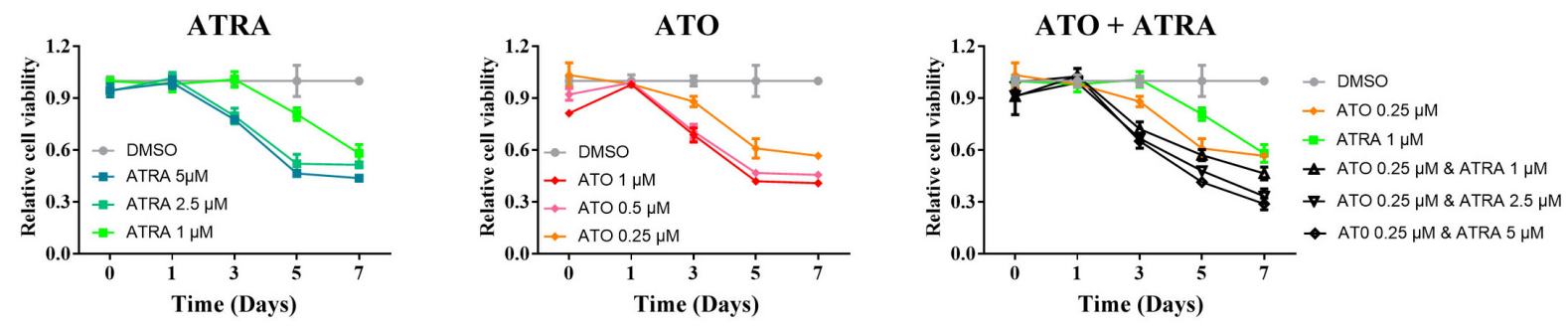

\section{E MCF-7R shPin1}
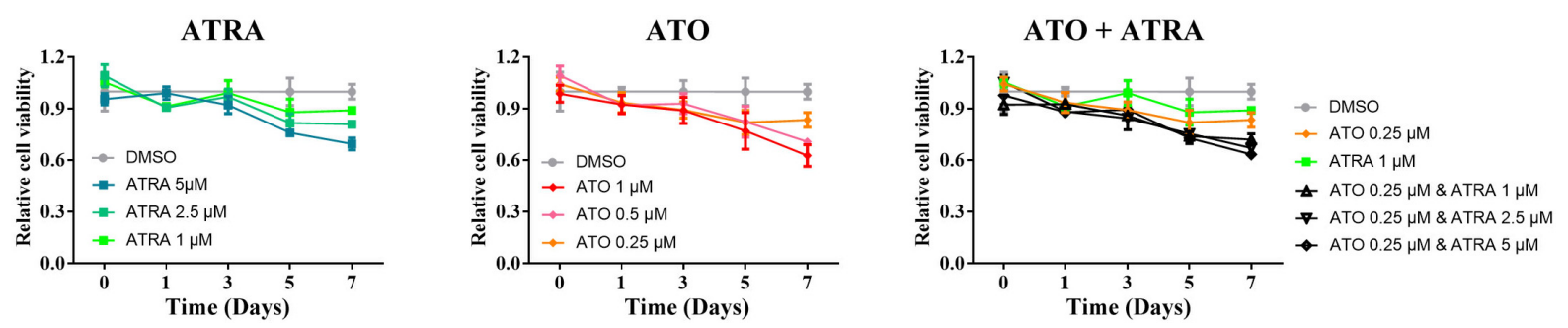

FIGURE 7 | ATRA and other Pin1 inhibitor has limited inhibitory effect on Pin1-low expressing cells. (A,B) ATRA shows little inhibitory effect on the viability of MCF-10A and HMLE cells. Cells were treated with increasing doses of ATRA for 7 days. (C) The effect of ATRA and ATO on reducing the level of Pin1 protein in MCF-7R cells. The concentration of ATRA and ATO were added to the culture medium as indicated for $48 \mathrm{~h}$. (D,E) ATRA and ATO show much less inhibitory effect on the proliferation of shPin1 cells than that of control MCF-7R cells. MCF-7R cells stably expressing scramble or Pin1 shRNA were treated with ATRA and ATO for 7 days.

suppressed the proliferation of these cells upon tamoxifen treatment (Supplementary Figures S4A,B, S10), suggesting that $\mathrm{ER} \alpha$ indeed contributed to TAMR in these cells.

To investigate the effects of ATRA on Pin1-low cells, we treated MCF-10A and HMLE with different doses of ATRA. ATRA exhibited very limited inhibitory effects on cell viability of these epithelial cells (Figures 7A,B), likely because ATRA selectively targets active Pin1 in cancer cells, but not in normal cells with low Pin1 levels (Wei et al., 2015). Thus these results demonstrated that ATRA inhibits cell growth of TAMR breast cancer, with little effects on normal cells.

We also treated MCF-7R and T47DR cells that had knocked down Pin1 with ATRA and ATO, a newly identified Pin1 inhibitor (Kozono et al., 2018). Both ATRA and ATO showed much less inhibitory effect on the proliferation of shPin 1 cells than that of control MCF-7R cells (Figures 7C-E and Supplementary Figure S8). Notably, although either ATRA or ATO could inhibit the proliferation of TAMR cells, the 


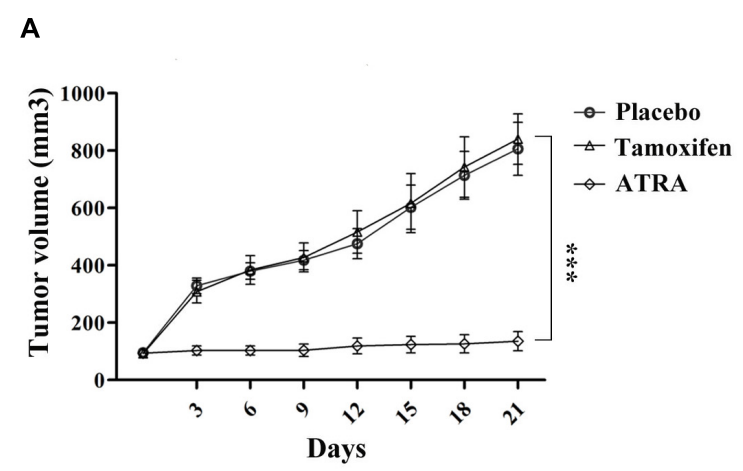

C

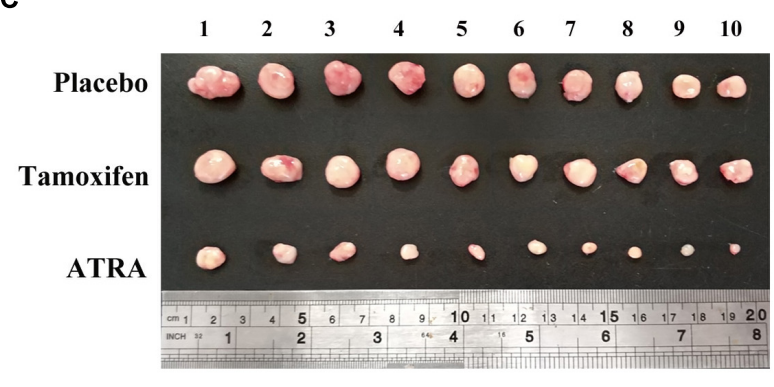

B
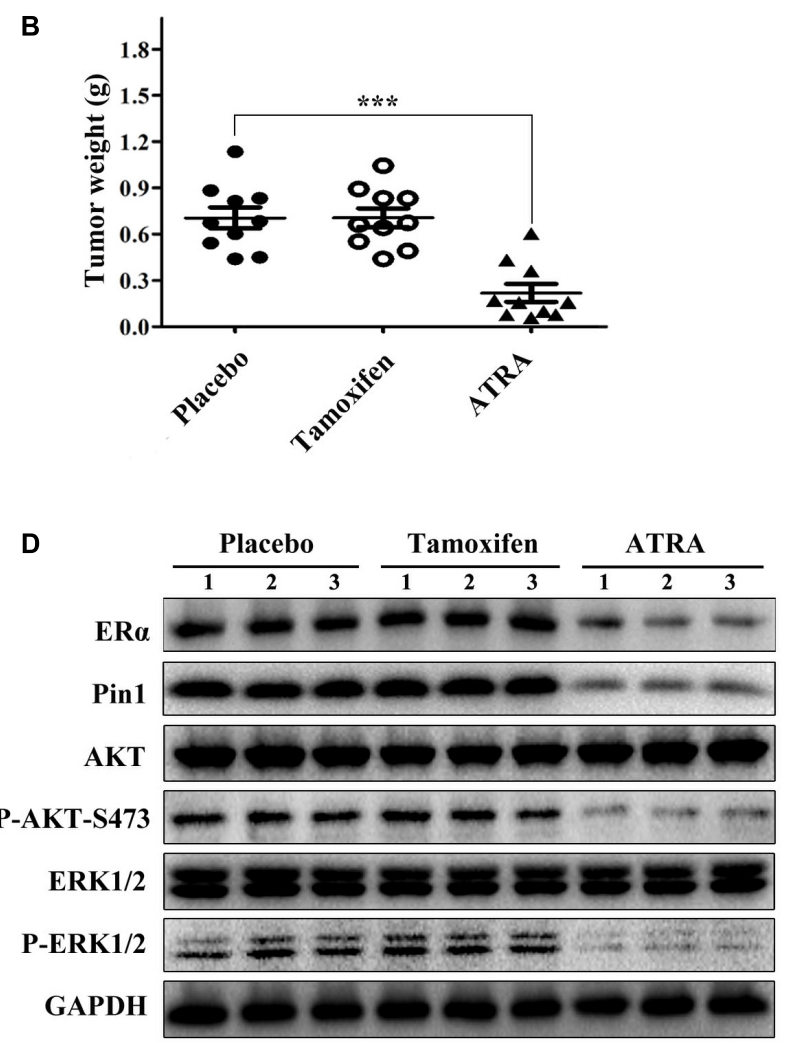

FIGURE 8 | ATRA suppresses the growth of TAMR breast cancer in vivo. (A) Growth curve of MCF-7R xenografts in nude mice. Tumor volumes were measured every 3 days. Error bars represent SD of ten mice, ${ }^{* * *} P<0.001$. (B) Slow-releasing ATRA pellet inhibits the tumor growth of MCF-7R xenografts in nude mice. The tumor weight represented the mean $\pm \mathrm{SD}$ of each group, ${ }^{* * *} P<0.001$. (C) MCF-7R xenografts were collected 3 weeks after treatment. (D) Representative immunoblots show Pin1, ER $\alpha, \mathrm{P}-\mathrm{AKT}$, and P-ERK1/2 levels in MCF-7R xenografts.

combination of ATRA + ATO effectively suppressed the cell viability in low dose (Figures 7D,E).

\section{ATRA Suppresses the Growth of TAMR Breast Cancer in vivo}

Given the remarkable effects of ATRA on inhibiting $\mathrm{ER} \alpha$, $\mathrm{AKT}$, and ERK1/2, as well as cell proliferation in tamoxifenresistant breast cancer in vitro, we next asked whether ATRA had therapeutic effect against TAMR breast tumors in vivo. We established MCF-7R xenografts and implanted 21-day slow-releasing ATRA tablets in nude mice. Tamoxifen showed no therapeutic effect on TAMR xenografts, whereas ATRA remarkably inhibited the growth of TAMR breast cancer cells in vivo (Figures 8A-C). In addition, ATRA significantly suppressed Pin1, ER $\alpha$, as well as the phosphorylation of AKT and ERK1/2 in the xenografts (Figure 8D and Supplementary Figure S8). Therefore, ATRA is effective in overcoming tamoxifen resistance in vivo.

\section{DISCUSSION}

Tamoxifen resistance is one of the major hurdles in treating breast cancer. A large body of evidence suggests that modulation of $\mathrm{ER} \alpha$ pathway and activation of pro-survival pathways are important factors of tamoxifen resistance (Cui et al., 2015; Ferraiuolo et al., 2017; Marsh et al., 2017; Zhang et al., 2017). Our study demonstrated that Pin1 was up-regulated in tamoxifenresistant breast cancer cells and relapsed breast cancer tissues. ATRA-induced Pin 1 degradation decreased the protein stability and transcription activity of $\mathrm{ER} \alpha$, as well as reduced the phosphorylation of pro-survival kinases AKT and ERK1/2 in tamoxifen-resistant breast cancer cells. Moreover, targeting Pin1 by ATRA inhibited cell growth in vitro, and exhibited anti-tumor effects in vivo against tamoxifen-resistant breast cancer. Our data suggest that ATRA is a potent drug in treating tamoxifenresistant breast cancer via suppressing multifactorial mechanisms of tamoxifen resistance.

Compelling evidence has demonstrated that decreased ER $\alpha$ expression and function contributes to intrinsic and acquired tamoxifen resistance (Cui et al., 2015; Ferraiuolo et al., 2017; Marsh et al., 2017; Zhang et al., 2017). Various clinical and experimental models suggest that tumor cells with acquired resistance to tamoxifen express low level of ER $\alpha$ (Stone et al., 2013; Lu et al., 2016). In the presence of tamoxifen, the resistant cells can still activate $\mathrm{ER} \alpha$, but through a ligand-independent way (He et al., 2018), or rely on non-ER $\alpha$ growth-promoting pathways for survival (Hur et al., 2004; Cannings et al., 2007; Mohseni et al., 
2014). Thus the low level of $E R \alpha$ is one of the key resources of growth signal that are available for the resistant cells to utilize. Previous study showed that Pin1 inhibited phosphorylationdependent ubiquitination and degradation of ER $\alpha$ in breast cancer cells (Rajbhandari et al., 2014). Here we found that Pin1 was up-regulated in tamoxifen-resistant breast cancer cells. This up-regulated Pin 1 prevented ER $\alpha$ from degradation, which substantially enhanced the ER $\alpha$ level in tamoxifen-resistant cells. Although ER $\alpha$ level was low in these resistant cells, it would be even lower if Pin1 was not up-regulated. In our clinical samples, ER $\alpha$ expression was high in more than $60 \%$ of recurrent breast cancer tissues. This may be because Pin 1 is frequently highly expressed in recurrent tumors, therefore preventing ER $\alpha$ from degradation, which substantially enhances the ER $\alpha$ level in relapsed tumors. Notably, this increased ER $\alpha$, just as the low level of $\mathrm{ER} \alpha$ in the resistant cells, is very likely activated via ligand independent way. This is supported by the evidence that phosphorylation of key serine residues of $\mathrm{ER} \alpha$, in particular serine 118 and 167, promotes re-activation of ER $\alpha$ in a ligandindependent manner (Garcia-Becerra et al., 2012). Pin1 has been reported to bind specifically to $\mathrm{pS} 118 \mathrm{ER} \alpha$ to isomerize the serine118-proline119 bond (Rajbhandari et al., 2012). Therefore, Pin 1 overexpression promotes the growth of tamoxifen-resistant breast cancer cells by up-regulating the ligand-independent $\mathrm{ER} \alpha$ activity.

In addition to the effects on $\mathrm{ER} \alpha$ stabilization, isomerization of phosphorylated ER $\alpha$ by Pin 1 directly increases endogenous ER $\alpha$ DNA binding activity (Rajbhandari et al., 2015). Our study showed that inhibiting Pin1 by ATRA suppressed nuclear $\mathrm{ER} \alpha$ expression and the transcription of $\mathrm{ER} \alpha$ target genes. Moreover, previous data suggest that besides affecting $\operatorname{ER} \alpha$, Pin1 may promote tamoxifen resistance of breast cancer by activating growth-promoting pathways (Khanal et al., 2012), down-regulating SMRT (Stanya et al., 2008) and cyclin dependent kinase (Khanal et al., 2012), facilitating tumor angiogenesis (Kim et al., 2009b, 2012) and epithelial-mesenchymal transition (Kim et al., 2009a). However, few studies assess the potential of Pin1 inhibitor in treating TAMR breast cancer in vitro and in vivo. Our study showed that ATRA decreased ER $\alpha$ level both in vitro and in vivo. Moreover, ATRA down-regulated phosphorylation of ER $\alpha$ at S118 and two important pro-survival kinases ERK1/2 and AKT. Thus, ATRA inhibits Pin 1 to overcome tamoxifen resistance in breast cancer cells at least at three levels: (1) promotes the degradation of ligand independent $\mathrm{ER} \alpha$, (2) suppresses the transactivation of $\mathrm{ER} \alpha$, (3) inhibits alternative growth pathways. Indeed, our results showed that ATRA exhibited potent anti-tumor activity against tamoxifenresistant breast cancer in vitro and in vivo.

All-Trans Retinoic Acid has been used to treat APL for a long period of time. Recently Wei et al. (2015) has discovered that ATRA is a Pin1 inhibitor which binds to Pin1's active site and accelerated its degradation. These findings make it possible to expand the application of ATRA to treat more types of cancer, especially solid tumors, because Pin 1 is overexpressed in a wide range of human cancers and regulates multiple cancer-driving pathways (Lu and Hunter, 2014; Zhou and Lu, 2016). Besides Wei et al. demonstrated that ATRA-induced Pin1 ablation inhibits triple-negative breast cancer cell growth (Wei et al., 2015), Liao et al. also reported the anti-tumor effect of ATRA in hepatocellular carcinoma (HCC) in vitro and in vivo (Liao et al., 2017; Yang et al., 2018). New Pin1 inhibitors have also been discovered to suppress the growth of cancer cells (Campaner et al., 2017; Kozono et al., 2018), even the tumor-initiating cells, as Pin1 promotes the self-renewal of these stem-like cancer cells (Luo et al., 2014; Rustighi et al., 2014, 2017). Our data showed that ATRA suppressed the cell proliferation of tamoxifen-resistant breast cancer cells, and effectively reduced the tumor growth of tamoxifen-resistant xenografts by promoting ER $\alpha$ degradation, decreasing $\mathrm{ER} \alpha$ transactivation, and inhibits the activation of ERK1/2 and AKT. Given that multiple survival pathways and factors contribute to tamoxifen resistance, blocking a single pathway may be ineffective to overcome the resistance. Therefore, ATRA may have the advantage of suppressing multifactorial mechanisms of tamoxifen resistance simultaneously.

Currently there are still obstacles of using ATRA to treat solid tumors in human. Regular ATRA has a half-life of only $45 \mathrm{~min}$ in humans. Although slow-releasing pellets can be implanted subcutaneously in mice, the formulation of ATRA pellet is different from that used for oral administration or intravenous injection in human therapies, and can't be applied to human yet. Novel controlled releasing formulation of ATRA for effective cancer therapy are being developed actively (Westervelt et al., 2002; Tsimberidou et al., 2006; Yang et al., 2018). In addition, ATRA concentration is high in treating solid tumors. Similar to the previous report that the combination of ATRA + ATO inhibited tumor-initiating cells (Kozono et al., 2018), we found that this combination could reduce ATRA concentration and effectively inhibited the growth of TAMR cells. Thus, studies are ongoing to increase the efficacy of ATRA by improving its formulation, or using ATRA as part of combination therapies.

In summary, our data have shown for the first time that targeting Pin1 by ATRA effectively inhibits the growth of tamoxifen resistant breast cancer. This new approach represents a potential therapeutic strategy for intrinsic tamoxifen-resistant patients and relapsed ER $\alpha$-positive breast cancer patients. Our findings shed new light on the molecular mechanism of ATRA in overcoming tamoxifen resistance and warrant future preclinical and clinical studies of ATRA in treating the tamoxifen resistant breast cancers.

\section{DATA AVAILABILITY STATEMENT}

All datasets generated for this study are included in the article/Supplementary Material.

\section{ETHICS STATEMENT}

The studies involving human participants were reviewed and approved by the Internal review and ethics boards of Sun Yatsen Memorial Hospital. The patients/participants provided their written informed consent to participate in this study. The animal study was reviewed and approved by the Animal Care and Use Committee of Sun Yat-sen University. 


\section{AUTHOR CONTRIBUTIONS}

M-LL and SH: conception and design. YL and YZ: development of methodology. YC, Z-ML, N-NL, and DL: acquisition of data. YC and SH: analysis and interpretation of data. M-LL and YY: writing, review, and/or revision of the manuscript. $\mathrm{XZ}$ and $\mathrm{KL}$ : technical and material support. M-LL and YY: study supervision.

\section{FUNDING}

This work was supported by grants from the National Natural Science Foundation of China (81572890, 81772837, and 81872370), Guangdong Science and Technology

\section{REFERENCES}

Ali, S., Metzger, D., Bornert, J. M., and Chambon, P. (1993). Modulation of transcriptional activation by ligand-dependent phosphorylation of the human oestrogen receptor A/B region. EMBO J. 12, 1153-1160. doi: 10.1002/j.14602075.1993.tb05756.x

Anbalagan, M., and Rowan, B. G. (2015). Estrogen receptor alpha phosphorylation and its functional impact in human breast cancer. Mol. Cell Endocrinol. 418(Pt 3), 264-272. doi: 10.1016/j.mce.2015.01.016

Arnold, S. F., Obourn, J. D., Jaffe, H., and Notides, A. C. (1995). Phosphorylation of the human estrogen receptor by mitogen-activated protein kinase and casein kinase II: consequence on DNA binding. J. Steroid Biochem. Mol. Biol. 55, 163-172. doi: 10.1016/0960-0760(95)00177-2

Bosch, A., Li, Z., Bergamaschi, A., Ellis, H., Toska, E., Prat, A., et al. (2015). PI3K inhibition results in enhanced estrogen receptor function and dependence in hormone receptor-positive breast cancer. Sci. Transl. Med. 7:283ra51. doi: 10.1126/scitranslmed.aaa4442

Campaner, E., Rustighi, A., Zannini, A., Cristiani, A., Piazza, S., Ciani, Y., et al. (2017). A covalent PIN1 inhibitor selectively targets cancer cells by a dual mechanism of action. Nat. Commun. 8:15772. doi: 10.1038/ncomms15772

Cannings, E., Kirkegaard, T., Tovey, S. M., Dunne, B., Cooke, T. G., and Bartlett, J. M. (2007). Bad expression predicts outcome in patients treated with tamoxifen. Breast Cancer Res. Treat. 102, 173-179. doi: 10.1007/s10549-0069323-8

Chen, W., Zheng, R., Baade, P. D., Zhang, S., Zeng, H., Bray, F., et al. (2016). Cancer statistics in China, 2015. CA Cancer J. Clin. 66, 115-132. doi: 10.3322/caac. 21338

Chu, J., Zhu, Y., Liu, Y., Sun, L., Lv, X., Wu, Y., et al. (2015). E2F7 overexpression leads to tamoxifen resistance in breast cancer cells by competing with E2F1 at miR-15a/16 promoter. Oncotarget 6, 31944-31957. doi: 10.18632/oncotarget. 5128

Cui, J., Yang, Y., Li, H., Leng, Y., Qian, K., Huang, Q., et al. (2015). MiR-873 regulates ERalpha transcriptional activity and tamoxifen resistance via targeting CDK3 in breast cancer cells. Oncogene 34, 3895-3907. doi: 10.1038/onc.2014. 430

de The, H., and Chen, Z. (2010). Acute promyelocytic leukaemia: novel insights into the mechanisms of cure. Nat. Rev. Cancer 10, 775-783. doi: 10.1038/ nrc2943

Deroo, B. J., and Korach, K. S. (2006). Estrogen receptors and human disease. J. Clin. Invest. 116, 561-570. doi: 10.1172/jci27987

Endoh, H., Maruyama, K., Masuhiro, Y., Kobayashi, Y., Goto, M., Tai, H., et al. (1999). Purification and identification of p68 RNA helicase acting as a transcriptional coactivator specific for the activation function 1 of human estrogen receptor alpha. Mol. Cell Biol. 19, 5363-5372. doi: 10.1128/mcb.19. 8.5363

Ferraiuolo, R. M., Tubman, J., Sinha, I., Hamm, C., and Porter, L. A. (2017). The cyclin-like protein, SPY1, regulates the ERalpha and ERK1/2 pathways promoting tamoxifen resistance. Oncotarget 8, 23337-23352. doi: 10.18632/ oncotarget.15578
Department (2017B030314026), Guangdong Natural Science Foundation (2018A0303130322), the Science and Technology Foundation of the Guangdong Province (2014A050503029 and 2019A050510016), Sun Yat-sen Initiative Program for Scientific Research (YXQH201701), and Elite Young Scholar Program of Sun Yat-sen Memorial Hospital (Y201701).

\section{SUPPLEMENTARY MATERIAL}

The Supplementary Material for this article can be found online at: https://www.frontiersin.org/articles/10.3389/fcell.2019.00322/ full\#supplementary-material

Garcia-Becerra, R., Santos, N., Diaz, L., and Camacho, J. (2012). Mechanisms of resistance to endocrine therapy in breast cancer: focus on signaling pathways, miRNAs and genetically based resistance. Int. J. Mol. Sci. 14, 108-145. doi: 10.3390/ijms14010108

Girault, I., Bieche, I., and Lidereau, R. (2006). Role of estrogen receptor alpha transcriptional coregulators in tamoxifen resistance in breast cancer. Maturitas 54, 342-351. doi: 10.1016/j.maturitas.2006.06.003

He, H., Sinha, I., Fan, R., Haldosen, L. A., Yan, F., Zhao, C., et al. (2018). c-Jun/AP-1 overexpression reprograms ERalpha signaling related to tamoxifen response in ERalpha-positive breast cancer. Oncogene 37, 2586-2600. doi: 10.1038/s41388018-0165-8

Herman, M. E., and Katzenellenbogen, B. S. (1996). Response-specific antiestrogen resistance in a newly characterized MCF-7 human breast cancer cell line resulting from long-term exposure to trans-hydroxytamoxifen. J. Steroid Biochem. Mol. Biol. 59, 121-134. doi: 10.1016/s0960-0760(96)00114-8

Huang, M. E., Ye, Y. C., Chen, S. R., Chai, J. R., Lu, J. X., Zhoa, L., et al. (1988). Use of all-trans retinoic acid in the treatment of acute promyelocytic leukemia. Blood 72, 567-572. doi: 10.1182/blood.v72.2.567.567

Hur, J., Chesnes, J., Coser, K. R., Lee, R. S., Geck, P., Isselbacher, K. J., et al. (2004). The Bik BH3-only protein is induced in estrogen-starved and antiestrogenexposed breast cancer cells and provokes apoptosis. Proc. Natl. Acad. Sci. U.S.A. 101, 2351-2356. doi: 10.1073/pnas.0307337101

Johansson, H. J., Sanchez, B. C., Mundt, F., Forshed, J., Kovacs, A., Panizza, E., et al. (2013). Retinoic acid receptor alpha is associated with tamoxifen resistance in breast cancer. Nat. Commun. 4:2175. doi: 10.1038/ncomms 3175

Johnston, S. R. (2010). New strategies in estrogen receptor-positive breast cancer. Clin. Cancer Res. 16, 1979-1987. doi: 10.1158/1078-0432.CCR-09-1823

Khanal, P., Yun, H. J., Lim, S. C., Ahn, S. G., Yoon, H. E., Kang, K. W., et al. (2012). Proyl isomerase Pin1 facilitates ubiquitin-mediated degradation of cyclin-dependent kinase 10 to induce tamoxifen resistance in breast cancer cells. Oncogene 31, 3845-3856. doi: 10.1038/onc.2011.548

Kim, J. A., Kim, M. R., Kim, O., Phuong, N. T., Yun, J., Oh, W. K., et al. (2012). Amurensin $\mathrm{G}$ inhibits angiogenesis and tumor growth of tamoxifen-resistant breast cancer via Pin1 inhibition. Food Chem. Toxicol. 50, 3625-3634. doi: 10.1016/j.fct.2012.07.027

Kim, M. R., Choi, H. K., Cho, K. B., Kim, H. S., and Kang, K. W. (2009a). Involvement of Pin1 induction in epithelial-mesenchymal transition of tamoxifen-resistant breast cancer cells. Cancer Sci. 100, 1834-1841. doi: 10. 1111/j.1349-7006.2009.01260.x

Kim, M. R., Choi, H. S., Yang, J. W., Park, B. C., Kim, J. A., and Kang, K. W. (2009b). Enhancement of vascular endothelial growth factor-mediated angiogenesis in tamoxifen-resistant breast cancer cells: role of Pin 1 overexpression. Mol. Cancer Ther. 8, 2163-2171. doi: 10.1158/1535-7163.MCT-08-1061

Knowlden, J. M., Hutcheson, I. R., Jones, H. E., Madden, T., Gee, J. M., Harper, M. E., et al. (2003). Elevated levels of epidermal growth factor receptor/c-erbB2 heterodimers mediate an autocrine growth regulatory pathway in tamoxifenresistant MCF-7 cells. Endocrinology 144, 1032-1044. doi: 10.1210/en.2002220620 
Kozono, S., Lin, Y. M., Seo, H. S., Pinch, B., Lian, X., Qiu, C., et al. (2018). Arsenic targets Pin1 and cooperates with retinoic acid to inhibit cancerdriving pathways and tumor-initiating cells. Nat. Commun. 9:3069. doi: 10 . 1038/s41467-018-05402-2

Lee, Y. J., and Gorski, J. (1996). Estrogen-induced transcription of the progesterone receptor gene does not parallel estrogen receptor occupancy. Proc. Natl. Acad. Sci. U.S.A. 93, 15180-15184. doi: 10.1073/pnas.93.26.15180

Liao, X. H., Zhang, A. L., Zheng, M., Li, M. Q., Chen, C. P., Xu, H., et al. (2017). Chemical or genetic Pin 1 inhibition exerts potent anticancer activity against hepatocellular carcinoma by blocking multiple cancer-driving pathways. Sci. Rep. 7:43639. doi: 10.1038/srep43639

Liao, Y., Wei, Y., Zhou, X., Yang, J. Y., Dai, C., Chen, Y. J., et al. (2009). Peptidylprolyl cis/trans isomerase Pin 1 is critical for the regulation of $\mathrm{PKB} / \mathrm{Akt}$ stability and activation phosphorylation. Oncogene 28, 2436-2445. doi: 10.1038/onc. 2009.98

Lu, K. P., and Zhou, X. Z. (2007). The prolyl isomerase PIN1: a pivotal new twist in phosphorylation signalling and disease. Nat. Rev. Mol. Cell Biol. 8, 904-916. doi: $10.1038 / \mathrm{nrm} 2261$

Lu, R., Hu, X., Zhou, J., Sun, J., Zhu, A. Z., Xu, X., et al. (2016). COPS5 amplification and overexpression confers tamoxifen-resistance in ERalphapositive breast cancer by degradation of NCoR. Nat. Commun. 7:12044. doi: $10.1038 /$ ncomms 12044

Lu, Z., and Hunter, T. (2014). Prolyl isomerase Pin1 in cancer. Cell Res. 24, 1033-1049. doi: 10.1038/cr.2014.109

Luo, M. L., Gong, C., Chen, C. H., Hu, H., Huang, P., Zheng, M., et al. (2015). The Rab2A GTPase promotes breast cancer stem cells and tumorigenesis via Erk signaling activation. Cell Rep. 11, 111-124. doi: 10.1016/j.celrep.2015.03.002

Luo, M. L., Gong, C., Chen, C. H., Lee, D. Y., Hu, H., Huang, P., et al. (2014). Prolyl isomerase Pin 1 acts downstream of miR200c to promote cancer stemlike cell traits in breast cancer. Cancer Res. 74, 3603-3616. doi: 10.1158/00085472.CAN-13-2785

Marsh, L. A., Carrera, S., Shandilya, J., Heesom, K. J., Davidson, A. D., Medler, K. F., et al. (2017). BASP1 interacts with oestrogen receptor alpha and modifies the tamoxifen response. Cell Death Dis. 8:e2771. doi: 10.1038/cddis.2017.179

Miller, T. E., Ghoshal, K., Ramaswamy, B., Roy, S., Datta, J., Shapiro, C. L., et al. (2008). MicroRNA-221/222 confers tamoxifen resistance in breast cancer by targeting p27Kip1. J. Biol. Chem. 283, 29897-29903. doi: 10.1074/jbc. M804612200

Mohseni, M., Cidado, J., Croessmann, S., Cravero, K., Cimino-Mathews, A., Wong, H. Y., et al. (2014). MACROD2 overexpression mediates estrogen independent growth and tamoxifen resistance in breast cancers. Proc. Natl. Acad. Sci. U.S.A. 111, 17606-17611. doi: 10.1073/pnas.1408650111

Namgoong, G. M., Khanal, P., Cho, H. G., Lim, S. C., Oh, Y. K., Kang, B. S., et al. (2010). The prolyl isomerase Pin 1 induces LC-3 expression and mediates tamoxifen resistance in breast cancer. J. Biol. Chem. 285, 23829-23841. doi: 10.1074/jbc.M109.092874

Nilsson, S., Koehler, K. F., and Gustafsson, J. A. (2011). Development of subtypeselective oestrogen receptor-based therapeutics. Nat. Rev. Drug Discov. 10, 778-792. doi: 10.1038/nrd3551

Nonclercq, D., Journe, F., Body, J. J., Leclercq, G., and Laurent, G. (2004). Ligandindependent and agonist-mediated degradation of estrogen receptor-alpha in breast carcinoma cells: evidence for distinct degradative pathways. Mol. Cell Endocrinol. 227, 53-65. doi: 10.1016/j.mce.2004.07.003

Osborne, C. K., and Schiff, R. (2005). Estrogen-receptor biology: continuing progress and therapeutic implications. J. Clin. Oncol. 23, 1616-1622. doi: 10. $1200 /$ jco.2005.10.036

Osborne, C. K., and Schiff, R. (2011). Mechanisms of endocrine resistance in breast cancer. Annu. Rev. Med. 62, 233-247.

Rajbhandari, P., Finn, G., Solodin, N. M., Singarapu, K. K., Sahu, S. C., Markley, J. L., et al. (2012). Regulation of estrogen receptor alpha N-terminus conformation and function by peptidyl prolyl isomerase Pin1. Mol. Cell Biol. 32, 445-457. doi: 10.1128/MCB.06073-11

Rajbhandari, P., Ozers, M. S., Solodin, N. M., Warren, C. L., and Alarid, E. T. (2015). Peptidylprolyl isomerase Pinl directly enhances the DNA binding functions of estrogen receptor alpha. J. Biol. Chem. 290, 13749-13762. doi: 10.1074/jbc.M114.621698

Rajbhandari, P., Schalper, K. A., Solodin, N. M., Ellison-Zelski, S. J., Ping Lu, K., Rimm, D. L., et al. (2014). Pin1 modulates ERalpha levels in breast cancer through inhibition of phosphorylation-dependent ubiquitination and degradation. Oncogene 33, 1438-1447. doi: 10.1038/onc.2013.78

Rustighi, A., Zannini, A., Campaner, E., Ciani, Y., Piazza, S., and Del Sal, G. (2017). PIN1 in breast development and cancer: a clinical perspective. Cell Death Dif. 24, 200-211. doi: 10.1038/cdd.2016.122

Rustighi, A., Zannini, A., Tiberi, L., Sommaggio, R., Piazza, S., Sorrentino, G., et al. (2014). Prolyl-isomerase Pin1 controls normal and cancer stem cells of the breast. EMBO Mol. Med. 6, 99-119. doi: 10.1002/emmm.201302909

Sanz, M. A., and Lo-Coco, F. (2011). Modern approaches to treating acute promyelocytic leukemia. J. Clin. Oncol. 29, 495-503. doi: 10.1200/jco.2010.32. 1067

Shao, W., Keeton, E. K., McDonnell, D. P., and Brown, M. (2004). Coactivator AIB1 links estrogen receptor transcriptional activity and stability. Proc. Natl. Acad. Sci. U.S.A. 101, 11599-11604. doi: 10.1073/pnas.0402997101

Sheeler, C. Q., Singleton, D. W., and Khan, S. A. (2003). Mutation of serines 104, 106 , and 118 inhibits dimerization of the human estrogen receptor in yeast. Endocr. Res. 29, 237-255. doi: 10.1081/erc- 120022321

Stanya, K. J., Liu, Y., Means, A. R., and Kao, H. Y. (2008). Cdk2 and Pin1 negatively regulate the transcriptional corepressor SMRT. J. Cell Biol. 183, 49-61. doi: $10.1083 /$ jcb.200806172

Stenoien, D. L., Patel, K., Mancini, M. G., Dutertre, M., Smith, C. L., O’Malley, B. W., et al. (2001). FRAP reveals that mobility of oestrogen receptor-alpha is ligand- and proteasome-dependent. Nat. Cell Biol. 3, 15-23. doi: 10.1038/ 35050515

Stone, A., Cowley, M. J., Valdes-Mora, F., McCloy, R. A., Sergio, C. M., GallegoOrtega, D., et al. (2013). BCL-2 hypermethylation is a potential biomarker of sensitivity to antimitotic chemotherapy in endocrine-resistant breast cancer. Mol. Cancer Ther. 12, 1874-1885. doi: 10.1158/1535-7163.MCT-13-0012

Sun, M., Paciga, J. E., Feldman, R. I., Yuan, Z., Coppola, D., Lu, Y. Y., et al. (2001). Phosphatidylinositol-3-OH Kinase (PI3K)/AKT2, activated in breast cancer, regulates and is induced by estrogen receptor alpha (ERalpha) via interaction between ERalpha and PI3K. Cancer Res. 61, 5985-5991.

Svensson, S., Jirstrom, K., Ryden, L., Roos, G., Emdin, S., Ostrowski, M. C., et al. (2005). ERK phosphorylation is linked to VEGFR2 expression and Ets2 phosphorylation in breast cancer and is associated with tamoxifen treatment resistance and small tumours with good prognosis. Oncogene 24, 4370-4379. doi: 10.1038/sj.onc. 1208626

Tsimberidou, A. M., Tirado-Gomez, M., Andreeff, M., O’Brien, S., Kantarjian, H., Keating, M., et al. (2006). Single-agent liposomal all-trans retinoic acid can cure some patients with untreated acute promyelocytic leukemia: an update of The University of Texas M. D. Anderson Cancer Center series. Leuk. Lymphoma 47, 1062-1068. doi: $10.1080 / 10428190500463932$

Wei, S., Kozono, S., Kats, L., Nechama, M., Li, W., Guarnerio, J., et al. (2015). Active Pin1 is a key target of all-trans retinoic acid in acute promyelocytic leukemia and breast cancer. Nat. Med. 21, 457-466. doi: 10.1038/nm.3839

Westervelt, P., Pollock, J. L., Oldfather, K. M., Walter, M. J., Ma, M. K., Williams, A., et al. (2002). Adaptive immunity cooperates with liposomal all-trans-retinoic acid (ATRA) to facilitate long-term molecular remissions in mice with acute promyelocytic leukemia. Proc. Natl. Acad. Sci. U.S.A. 99, 9468-9473. doi: 10.1073/pnas. 132657799

Wijayaratne, A. L., and McDonnell, D. P. (2001). The human estrogen receptoralpha is a ubiquitinated protein whose stability is affected differentially by agonists, antagonists, and selective estrogen receptor modulators. J. Biol. Chem. 276, 35684-35692. doi: 10.1074/jbc.m101097200

Wu, Y., Zhang, Z., Cenciarini, M. E., Proietti, C. J., Amasino, M., Hong, T., et al. (2018). Tamoxifen resistance in breast cancer is regulated by the EZH2ERalpha-GREB1 transcriptional axis. Cancer Res. 78, 671-684. doi: 10.1158/ 0008-5472.CAN-17-1327

Xiong, R., Zhao, J., Gutgesell, L. M., Wang, Y., Lee, S., Karumudi, B., et al. (2017). Novel Selective Estrogen Receptor Downregulators (SERDs) developed against treatment-resistant breast cancer. J. Med. Chem. 60, 1325-1342. doi: 10.1021/ acs.jmedchem.6b01355

Yager, J. D., and Davidson, N. E. (2006). Estrogen carcinogenesis in breast cancer. N. Engl. J. Med. 354, 270-282.

Yang, D., Luo, W., Wang, J., Zheng, M., Liao, X. H., Zhang, N., et al. (2018). A novel controlled release formulation of the Pin1 inhibitor ATRA to improve liver cancer therapy by simultaneously blocking multiple cancer pathways. J. Control Release 269, 405-422. doi: 10.1016/j.jconrel.2017.11.031 
Zhang, J., Zhou, C., Jiang, H., Liang, L., Shi, W., Zhang, Q., et al. (2017). ZEB1 induces ER-alpha promoter hypermethylation and confers antiestrogen resistance in breast cancer. Cell Death Dis. 8, e2732. doi: 10.1038/cddis.20 17.154

Zhang, X., Peng, D., Xi, Y., Yuan, C., Sagum, C. A., Klein, B. J., et al. (2016). G9a-mediated methylation of ERalpha links the PHF20/MOF histone acetyltransferase complex to hormonal gene expression. Nat. Commun. 7:10810. doi: 10.1038/ncomms 10810

Zhou, X. Z., and Lu, K. P. (2016). The isomerase PIN1 controls numerous cancerdriving pathways and is a unique drug target. Nat. Rev. Cancer. 16, 463-478. doi: $10.1038 /$ nrc.2016.49
Conflict of Interest: The authors declare that the research was conducted in the absence of any commercial or financial relationships that could be construed as a potential conflict of interest.

Copyright (C) 2019 Huang, Chen, Liang, Li, Liu, Zhu, Liao, Zhou, Lu, Yao and Luo. This is an open-access article distributed under the terms of the Creative Commons Attribution License (CC BY). The use, distribution or reproduction in other forums is permitted, provided the original author(s) and the copyright owner(s) are credited and that the original publication in this journal is cited, in accordance with accepted academic practice. No use, distribution or reproduction is permitted which does not comply with these terms. 